\title{
A long-lasting dipeptidyl peptidase-4 inhibitor, teneligliptin, as a preventive drug for the development of hepatic steatosis in high-fructose diet-fed ob/ob mice
}

\author{
KEN NAKAMURA, SHINYA FUKUNISHI, KEISUKE YOKOHAMA, HIDEKO OHAMA, \\ YUSUKE TSUCHIMOTO, AKIRA ASAI, YASUHIRO TSUDA and KAZUHIDE HIGUCHI
}

Second Department of Internal Medicine, Osaka Medical College, Takatsuki, Osaka 569-8686, Japan

Received October 4, 2016; Accepted February 1, 2017

DOI: $10.3892 /$ ijmm.2017.2899

\begin{abstract}
Non-alcoholic fatty liver disease (NAFLD) occurs in patients with components of metabolic syndrome such as type 2 diabetes mellitus (T2DM). At present, the central pathophysiological problem in patients afflicted with NAFLD is insulin resistance. In this study, we aimed to determine the effects of a dipeptidyl peptidase-4 (DPP-4) inhibitor, teneligliptin, on the development of NAFLD in ob/ob mice. Five-week-old male ob/ob mice were divided into 4 experimental groups as follows: a group in which they were fed a high carbohydrate diet (HCD) for 8 weeks $(n=8)$ as controls (control group 1), a group in which they were fed HCD supplemented with $0.018 \%$ teneligliptin for 8 weeks $(n=8)$ (teneligliptin group 1), a group in which they were
\end{abstract}

Correspondence to: Dr Shinya Fukunishi, Second Department of Internal Medicine, Osaka Medical College, 2-7 Daigaku-machi, Takatsuki, Osaka 569-8686, Japan

E-mail: in2104@osaka-med.ac.jp

Abbreviations: NAFLD, non-alcoholic fatty liver disease; T2DM, type 2 diabetes mellitus; NASH, non-alcoholic steatohepatitis; GLP-1, glucagon-like peptide-1; GIP, glucose-dependent insulinotropic polypeptide; DPP-4, dipeptidyl peptidase-4; HCD, high carbohydrate diet; AST, aspartate aminotransferase; ALT, alanine aminotransferase; GA, glico albumin; T-CHO, total cholesterol; TG, triglyceride; FFA, free fatty acid; H\&E, hematoxylin and eosin; GTT, glucose tolerance test; TNF, tumor necrosis factor; IFN, interferon; IL, interleukin; SREBP-1c, sterol regulatory element binding protein-1c; ChREBP, carbohydrate response element binding protein; FAS, fatty acid synthase; SCD-1, stearoyl-CoA desaturase-1; PPAR, peroxisome proliferator-activated receptors; ACL, ATP-citrate lyase; CoA, coenzyme A; ACC, acetyl-CoA carboxylase; AMPK, AMP-activated protein kinase; CPT-1, carnitine palmitoyltransferase-1; MCAD, medium-chain acyl-CoA dehydrogenase; LCAD, long-chain acyl-CoA dehydrogenase; $\mathrm{ECAH}$, enoyl-CoA hydratase; $\mathrm{HACDH}, 3$-hydroxyacyl-CoA dehydrogenase; bKACTB, 3-ketoacyl-CoA thiolase; IRS, insulin receptor substrate; PI3K, phosphatidylinositol-3-kinase; PEPCK, phosphoenolpyruvate carboxykinase; G6Pase, glucose-6-phosphatase

Key words: dipeptidyl peptidase-4 inhibitor, insulin sensitivity, nonalcoholic fatty liver disease, preventative drug, type 2 diabetes fed HCD for 12 weeks ( $n=8$ ) as controls (control group 2), and another group in which they were fed only HCD for 4 weeks, and the HCD was then supplemented with $0.018 \%$ teneligliptin for 8 weeks $(n=8)$ (teligliptin group 2). Hepatic steatosis was observed in all mice in the control group fed the HCD, but only mild hepatic steatosis was observed in teneligliptin group 1. Mice in teneligliptin group 1 fed the diet containing teneligliptin had lower hepatic triglyceride (TG) and free fatty acid (FFA) levels. Mice in teneligliptin group 1 exhibited improvement of insulin resistance; however, those in teneligliptin group 2 did not show any improvement of insulin resistance. Our results thus suggest that teneligliptin may be used as a preventative, but not as a treatment drug for the development of NAFLD.

\section{Introduction}

A hallmark of metabolic syndrome is the expansion of the visceral adipose tissue, which is under a state of chronic inflammation (1). Non-alcoholic fatty liver disease (NAFLD) occurs in patients with components of metabolic syndrome such as type 2 diabetes mellitus (T2DM), obesity, hypertension and hyperlipidemia. Histological changes of NAFLD range over a wide spectrum, extending from simple steatosis to non-alcoholic steatohepatitis (NASH), liver cirrhosis and liver failure, and sometimes, even hepatocellular carcinoma (2). In Western countries, the prevalence of NAFLD in the general population ranges from $15-39 \%(3,4)$. It is considered that the prevalence of NAFLD will continue to increase. However, effective drug therapy for NAFLD has not yet been established. Thus, studies aiming at exploring strategies for the treatment of NAFLD are of utmost importance.

At present, the central pathophysiological problem in patients afflicted with NAFLD is insulin resistance. The incretin hormones glucagon-like peptide-1 (GLP-1) and glucose-dependent insulinotropic polypeptide (GIP) are released from the gastrointestinal tract in response to a meal $(5,6)$. GLP-1 regulates plasma glucose levels by inhibiting glucagon secretion in a glucose-dependent manner, which results in reduced food intake and delaying gastric emptying. The actions of GLP-1 in vivo are short-lived due to their rapid degradation and inactivation by the enzyme dipeptidyl peptidase-4 (DPP-4) $(7,8)$. DPP-4 inhibitors have been demonstrated to improve glycemic 
control, in particular postprandial hyperglycemic control, in patients with T2DM. Several DPP-4 inhibitors have entered the market and have been reported to improve postprandial hyperglycemia (9-11). It has previously been reported that sitagliptin, a DPP-4 inhibitor, prevents the development of hepatic steatosis in mice (12).

Teneligliptin is an orally available and novel chemotype prolylthiazolidine-based DPP-4 inhibitor. It was synthesized in an effort to search for more potent and long-lasting DPP-4 inhibitors (13). We aimed to determine the effects of teneligliptin on the development of NAFLD in ob/ob mice with diet-induced obesity and T2DM.

\section{Materials and methods}

Chemicals and diets. The DPP-4 inhibitor, teneligliptin hydrogenbromide hydrate (3-[(2S,4S)-4-[4-(3-methyl-1-phenyl-1Hpyrazol-5-yl)piperazin-1-yl]pyrrolidin-2-yl-carbonyl] thiazolidine hemipentahydrogenbromide hydrate) (teneligliptin), used in this study was obtained from Tanabe Mitsubishi Pharma Corp. (Osaka, Japan). Teneligliptin was administrated orally by premixing with the high carbohydrate diet (HCD) to a concentration of $0.018 \%$ as this concentration of teneligliptin has been used to treat patients with T2DM. The HCD (Oriental Bio Service, Kyoto, Japan) contains $5 \%$ of calories from fat, $21 \%$ from protein, and $69 \% 60 \%$ fructose) from complex carbohydrates.

Animals. Obese male (ob/ob) 5-week-old mice were obtained from Oriental Bio Service. These mice have been extensively used as a naturally occurring model of hepatic steatosis. These mice are leptin-deficient as a mutation in the ob gene encoding leptin transcription prevents its biosynthesis (14).

Experimental design. After weaning, the mice were divided into 4 experimental groups for two purposes: one purpose was to determine whether teneligliptin can be used as a preventive drug for the development of NAFLD (experiment for prevention of NAFLD), and the other was to determine whether teneligliptin can be used as a treatment drug for NAFLD (experiment for treatment of NAFLD). The experimental design was as follows: 5-week-old male ob/ob mice, which develop T2DM and NAFLD by being fed a HCD, were divided into a group in which they were fed HCD for 8 weeks $(n=8)$ as controls (control group 1), and another in which they were fed HCD supplemented with $0.018 \%$ teneligliptin for 8 weeks $(n=8)$ (teneligliptin group 1 ) (experiment for prevention of NAFLD). In addition, another 5-week-old male ob/ob mice were divided into a group in which they were fed HCD for 12 weeks $(n=8)$ as controls (control group 2), and another group in which they were fed only HCD for 4 weeks, and the HCD was then supplemented with $0.018 \%$ teneligliptin for 8 weeks $(n=8)$ (teligliptin group 2$)$ (experiment for treatment of NAFLD). Mice were allowed free access to food, with a 12-h light/12-h dark cycle under conditions of controlled temperature $\left(22 \pm 1^{\circ} \mathrm{C}\right)$ and humidity $(50 \pm 10 \%)$. Food intake was measured daily, while individual body weight was recorded once a week. Within each group, 8 mice were fasted overnight prior to euthanasia. All mice were sacrificed after completing their respective dietary regimens, and the livers of the individual animals were weighed. The livers were removed, and part of the samples were placed in formalin, while the remainder was snap-frozen and stored at $-80^{\circ} \mathrm{C}$. All surgical and experimental procedures were performed according to the guidelines for the care and use of animals approved by Osaka Medical College, Takatsuki, Japan.

Assay for plasma hepatic and metabolic parameters. Blood samples were obtained by cardiac puncture and separated by centrifugation $(12,000 \mathrm{rpm}$ for $15 \mathrm{~min})$ as plasma. The levels of blood biochemical parameters, including aspartate aminotransferase (AST), alanine aminotransferase (ALT), glico albumin (GA), total-cholesterol (T-CHO), glucose and insulin were measured by a local laboratory that performs clinical analyses (Oriental Yeast Co. Ltd., Kyoto, Japan).

Assay for hepatic lipid content. Hepatic tissues were homogenized with a Janke and Kunkel Polytron homogenizer (ULTRA-TURRAX TP18/1051; IKA-Labortechnik, Staufen, Germany) in buffer (pH 7.4) containing $20 \mathrm{mM}$ Tris $\mathrm{HCl}, 1 \mathrm{mM}$ EGTA and $2 \mathrm{mM}$ EDTA, and treated with protease inhibitor (2 $\mu \mathrm{g} / \mathrm{ml}$, leupeptin cocktail). Hepatic tissue triglyceride (TG) levels and free fatty acid (FFA) levels were measured by a local laboratory that performs clinical analyses (SRL Co. Ltd., Tokyo, Japan).

Assay for plasma GLP-1 concentration. Total plasma GLP-1 concentrations were measured using a GLP-1, active from assay kit-IBL according to the manufacture's instructions (Immuno-Biological Laboratories Co., Ltd., Gunma, Japan).

Assay for DPP-4 activity. To examine the potential of direct inhibitory activity against DPP-4, $10 \mu \mathrm{l}$ of plasma was mixed with $90 \mu \mathrm{l}$ of assay buffer. Assays were reacted for $30 \mathrm{~min}$ at room temperature, and the released AMC was determined fluoromerically using Fuluorskan Ascent FL (375-nm excitation and 460-nm emissions; Thermo Fisher Scientific, Waktham, MA, USA). DPP-4 activity was determined with an AMC standard curve. The $50 \%$ inhibitory concentration against DPP-4 was calculated from the enzyme reaction curves the SAS system version 8.2 (SAS Institute, Cary, NC, USA).

Histological analysis of hepatic tissue. Liver sections were examined blindly from different lobes of each mouse. Liver tissues were fixed in $10 \%$ buffered formaldehyde, and then embedded in paraffin. A 4-mm-thick section cut from a paraffin-embedded block was stained with hematoxylin and eosin (H\&E) or Oil Red O (both from Applied Medical Research, Osaka, Japan). These sections were evaluated for fat content by the absence of staining. For hepatic steatosis: grade 0 , no fat; grade 1 , steatosis occupying $<33 \%$ of hepatic parenchyma; grade 2, 33-66\% of the hepatic parenchyma; grade $3,>66 \%$ of the hepatic parenchyma. For inflammatory cell infiltration: grade 0 , none; grade 1, 1-2 foci/field; grade 2, 3-4 foci/field; grade 3, >4 foci/field. For ballooning degeneration of the hepatocytes: grade 0 , absent; grade 1 , very mild inflammation; grade 2, mild-to-moderate portal inflammation; grade 3, intraacinar inflammation and moderate portal inflammation. For hepatic fibrosis: stage 0, none; stage 1, mild, perisinusoidal; stage 2, moderate, perisinusoidal fibrosis; stage 3, periportal fibrosis; stage 4, bridging fibrosis (15). 
Table I. Primer sequences used for the real-time polymerase chain reaction.

\begin{tabular}{|c|c|c|}
\hline Gene & Primer sequences (sense) & Primer sequences (antisense) \\
\hline TNF- $\alpha$ & 5'-ACCTTGTTGCCTCCTCTT-3' & 5'-GTTCAGTGATGTAGCGACAG-3' \\
\hline IL-1 $\beta$ & 5'-TCCAGGATGAGGACATGAGCAC-3' & 5'-GAACGTCACACACCAGCAGGTTA-3' \\
\hline IL-6 & 5'-TTCCTCACTGTGGTCAGA-3' & 5'-CATTCATATTGTCAGTTCTTCGTA-3' \\
\hline IFN- $\gamma$ & 5'-CGGCACAGTCATTGAAAGCCTA-3' & 5'-GTTGCTGATGGCCTGATTGTC-3' \\
\hline SREBP-1c & 5'-GGTACCTGCGGGACAGCTTA-3' & 5'-CCGTGAGCTACCTGGACTGAA-3' \\
\hline FAS & 5'-TACAGATGGCAGCAAGGA-3' & 5'-TGATACAGAGAGCAGATGAGT-3' \\
\hline ChREBP & 5'-TCGTGTAGACAACAAC-3' & 5'-ATATTGAACCGCCTCT-3' \\
\hline PPAR- $\alpha$ & 5'-ATGGCAGCAATATCAGAG-3' & 5'-AGCAGTAAAGTATCATATCAAAG-3' \\
\hline PPAR- $\gamma$ & 5'-GAAGACAGAGACAGACAT-3' & 5'-GCAATCAATAGAAGGAACA-3' \\
\hline SCD-1 & 5'-CTGGCTGGAGAGTCATCA-3' & 5'-TAACGAGGACGACAATACAATC-3' \\
\hline CPT1A & 5'-GACTACTTGCTAACCTCTGT-3' & 5'-GACACTGGAGACCTGAGA-3' \\
\hline ACC1 & 5'-ATCATAACTCGTATAACATCCA-3' & 5'-CAGGTTAAGGCTCAGACT-3' \\
\hline ACL & 5'-ACCCAGACATGCGAGTGCAG-3' & 5'-CCGTCCACATTCAGGATAAGATTTG-3' \\
\hline MCAD & 5'-CGGAGGAACCTGTCTTCA-3' & 5'-GGCTAAGGACCAATCATTGT-3' \\
\hline LCAD & 5'-GACATCTGCCTACATCCT-3' & 5'-TCTCTCCCTGTGTTAATCTT-3' \\
\hline ECAH & 5'-AGTCTATTCAAGTCACAAGT-3' & 5'-ATGGCATTCCTCTTCTCT-3' \\
\hline $\mathrm{HACDH}$ & 5'-ATCTTAACCATCACTGTC-3' & 5'-TAGTAGAGTCAATTCATAGG-3' \\
\hline bKACTB & 5'-AGGTTGTCACGCTACTCA-3' & 5'-ATCCCAGTCCCGATACAC-3' \\
\hline $\mathrm{PI} 3 \mathrm{~K}$ & 5'-GCAGTTAAGAAGCACA-3' & 5'-GTATGAAGCAGGAGAG-3' \\
\hline IRS-1 & 5'-GCCTTCCATATAGTTA-3' & 5'-GAACCATCATCATCTC-3' \\
\hline IRS-2 & 5'-CCATCCTTTGCCCACA-3' & 5'-GTACTGCTGCCTTCAC-3' \\
\hline AMPK & 5'-AAGCCGACCCAATGACATCA-3' & 5'-CTTCCTTCGTACACGCAAAT-3' \\
\hline G6Pase & 5'-GTGGCAGTGGTCGGAGACT-3' & 5'-ACGGGCGTTGTCCAAAC-3' \\
\hline PEPCK & 5'-TGCCCGGGTGGAAGGTCGAA-3' & 5'-TGGGCACATGGTTCCGCGTC-3' \\
\hline
\end{tabular}

TNF- $\alpha$, tumor necrosis factor- $\alpha$; IL, interleukin; IFN- $\gamma$, interferon- $\gamma$; SREBP-1c, sterol regulatory element binding protein- $1 \mathrm{c}$; FAS, fatty acid synthase; ChREBP, carbohydrate response element binding protein; PPAR, peroxisome proliferator-activated receptor; SCD-1, stearoyl-CoA desaturase-1; CPT, carnitine palmitoyltransferase; ACC1, acetyl-CoA carboxylase 1; ACL, ATP-citrate lyase; MCAD, medium-chain acyl-CoA dehydrogenase; LCAD, long-chain acyl-CoA dehydrogenase; ECAH, enoyl-CoA hydratase; HACDH, 3-hydroxyacyl-CoA dehydrogenase; bKACTB, 3-ketoacyl-CoA thiolase; PI3K, phosphatidylinositol-3-kinase; IRS, insulin receptor substrate; AMPK, AMP-activated protein kinase; G6Pase, glucose-6-phosphatase; PEPCK, phosphoenolpyruvate carboxykinase.

Glucose tolerance test (GTT). Mice used in the experiment for prevention of NAFLD at 9 weeks of age and those in the experiment for the treatment of NAFLD at 13 weeks of age were fasted overnight. After measuring the body weight, $20 \%$ glucose was injected into each mouse i.p. at $100 \mu \mathrm{l} / 10 \mathrm{~g}$ body weight. The blood glucose level was measured with a glucose meter 15-min intervals during a 2 -h course. In order to analyze insulin secretion during GTT, blood was collected 0,15 and 120 min after glucose injection. The level of insulin was measured by a local laboratory that does clinical analyses (Oriental Yeast Co. Ltd.).

Real-time PCR. Tissue specimens were preserved in RNAlater reagent (Qiagen, Valencia, CA, USA) until the isolation of total RNA. Total RNA was isolated from the liver tissue using a QIA shredder and an RNeasy kit (Qiagen). cDNA was prepared using the TaqMan reverse transcriptase kit (Qiagen). Real-time PCR was performed on total RNA using the StrataScript First Strand cDNA Synthesis kit and FullVelocity SYBR-Green qPCR Master Mix (Stratagene, La Jolla, CA, USA) according to the manufacturer's protocol. Primers for real-time PCR were designed using Beacon Designer software version 2.12, according to the parameters outlined in the Bio-Rad iCycler Manual, using reference mRNA sequences accessed through Gene Bank and as shown in Table I. All probes used in the TaqMan Gene Expression assays were purchased from Applied Biosystems (Foster City, CA, USA). PCR reactions were carried outin the iCycler Thermal Cycler (Bio-Rad Laboratories, Hercules, CA, USA). PCR products were detected using the iCycler iQ Real-Time PCR detection system (Bio-Rad Laboratories). The relative amount of mRNA was calculated by comparative cycle time determination with ribosomal protein RPL32 as the invariant control. Gene expression values were calculated based on the $\Delta \Delta \mathrm{Ct}$ method. The results were expressed as a fold increase in expression relative to the control group.

Statistical analysis. Data are presented as the means \pm standard error of the mean. Statistical analyses were performed using the Student's t-test. Values of $\mathrm{p}<0.05$ were considered to indicate statistically significant differences.

\section{Results}

Effect of treatment and diets on body weight and liver/body weight ratio of mice in each experimental group. As shown Fig. 1A, at the end of the experimental period, there was no significant difference in the weight of the mice in both 

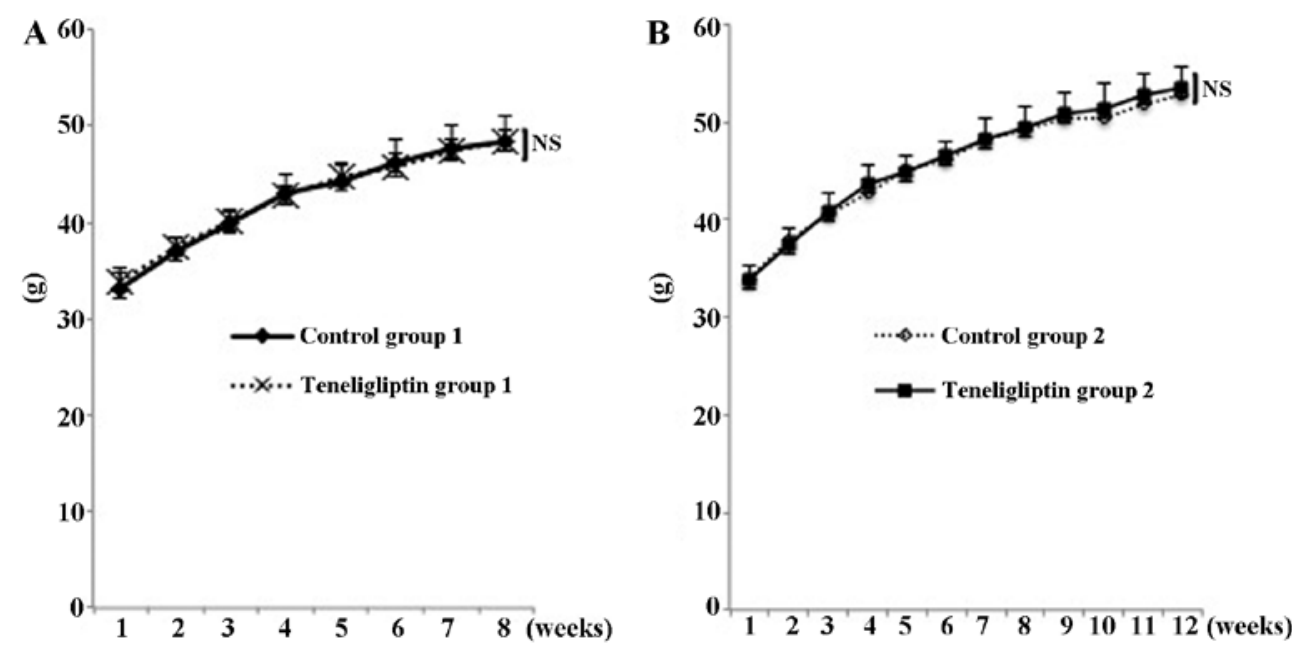

Figure 1. (A) Experimental course of body weight of all mice in the experiment for the prevention for non-alcoholic fatty liver disease (NAFLD). Same degree of body weight were observed in the two groups. (B) Experimental course of body weight of all mice in the experiment for the treatment of NAFLD. Same degree of body weight were observed in the two groups. NS, no significant difference.

groups $(48.40 \pm 2.74$ and $48.35 \pm 1.15 \mathrm{~g}$ in both groups of mice, respectively; $\mathrm{p}<0.05$ ) (experiment for prevention of NAFLD). In addition, as shown Fig. 1B, at the end of experimental period, there was also no significant difference in the weight of mice in the both groups $(52.75 \pm 2.33$ and $53.58 \pm 2.07 \mathrm{~g}$ in both groups of mice, respectively; $\mathrm{p}<0.05$ ) (experiment for treatment of NAFLD). As shown Table II-A, the ratio of liver weight to body weight was not significantly different in both groups of mice $(5.82 \pm 1.10$ and $5.80 \pm 0.98 \%$ in both group of mice, respectively; $p<0.05$ ) (experiment for prevention of NAFLD). In addition, as shown Table II-B, the ratio of liver weight to body weight was not significantly difference in both groups of mice $(6.81 \pm 1.08$ and $6.80 \pm 1.08 \%$ in both group of mice, respectively; $\mathrm{p}<0.05$ ) (experiment for treatment of NAFLD).

Plasma and hepatic biochemical parameters. To examine whether teneligliptin if used as a preventive drug for NAFLD affects liver damage and steatosis, we quantified the plasma levels of AST, ALT, T-CHO hepatic TG and FFA. The plasma AST $(293.88 \pm 93.28$ vs. $183.2 \pm 86.71 \mathrm{IU} / 1, \mathrm{p}<0.05)$ and ALT levels $(239.24 \pm 80.91$ vs. $150.76 \pm 81.99 \mathrm{IU} / 1, \mathrm{p}<0.05)$ were significantly different in the teneligliptin group 1 from the control group 1 (Table II-A). Mice fed the diet containing teneligliptin had lower plasma levels of T-CHO $(216.0 \pm 1$ 7.01 vs. $198.29 \pm 12.93 \mathrm{mg} / \mathrm{dl}, \mathrm{p}<0.05)$, a lower hepatic TG content $(105.69 \pm 4.89$ vs. $86.85 \pm 6.61 \mathrm{mg} / \mathrm{dl}, \mathrm{p}<0.05)$ and a lower hepatic FFA content $(111.66 \pm 5.71$ vs. $82.81 \pm 3.93 \mu \mathrm{Eq} / 1$, $\mathrm{p}<0.05$ ) (Table II-A).

Next, to determine whether teneligliptin if used as a treatment drug for NAFLD affects liver damage and steatosis, we quantified the plasma levels of AST, ALT, T-CHO hepatic TG and FFA. The plasma AST $(140.09 \pm 61.53$ vs. $125.87 \pm 73.80 \mathrm{IU} / \mathrm{l}, \mathrm{p}<0.05)$ levels were not significantly different in both groups. The ALT levels $(121.03 \pm 52.21$ vs. $233.80 \pm 70.09 \mathrm{IU} / 1, \mathrm{p}<0.05)$ were significantly different in the teneligliptin group 2 compared to the control group 2 (Table II-B). Mice fed the diet containing teneligliptin had higher plasma levels of T-CHO compared to the HCD-fed mice $(227.88 \pm 16.97$ vs. $270.83 \pm 37.06 \mathrm{mg} / \mathrm{dl}, \mathrm{p}<0.05)$. The hepatic TG content $(107.71 \pm 5.62$ vs. $108.91 \pm 5.79 \mathrm{mg} / \mathrm{dl}, \mathrm{p}<0.05)$ and hepatic
FFA content $(132.66 \pm 3.17$ vs. $134.18 \pm 3.92 \mu \mathrm{Eq} / 1, \mathrm{p}<0.05)$ were not significantly different in the both groups (Table II-B).

Plasma glucose, insulin and GA. Mice fed the diet containing teneligliptin as a preventive drug for NAFLD had lower fasting blood glucose levels $(314.0 \pm 34.98$ vs. 264 . $33 \pm 31.63 \mathrm{mg} / \mathrm{dl}, \mathrm{p}<0.05$ ), lower fasting plasma insulin levels (3.91 \pm 3.59 vs. $1.03 \pm 0.47 \mathrm{ng} / \mathrm{dl}, \mathrm{p}<0.05)$ and a lower level of GA $(2.22 \pm 0.16$ vs. $1.72 \pm 0.62 \%, \mathrm{p}<0.05)$ (Table II-A). Mice fed the diet containing teneligliptin as a treatment drug for NAFLD exhibited no significant difference in fasting blood glucose levels $(278.50 \pm 31.52$ vs. $313.38 \pm 44.14 \mathrm{mg} / \mathrm{dl}, \mathrm{p}<0.05)$, fasting plasma insulin levels $(1.24 \pm 0.37$ vs. $1.16 \pm 0.38 \mathrm{ng} / \mathrm{dl}, \mathrm{p}<0.05)$ and the level of GA $(2.07 \pm 0.12$ vs. $1.50 \pm 0.71 \%, p<0.05)$, compared with the mice fed the HCD alone (Table II-B).

Concentration of plasma GLP-1. Since a previous study demonstrated that GLP-1 prevents the development of NAFLD (16), we thus examined the concentration of GLP-1 in this study. The plasma concentration of GLP-1 was higher in both teneligliptin groups (Fig. 2).

Effects of teneligliptin on DPP-4 activity. We wished to examine whether teneligliptin affects plasma DPP-4 activity in the two experimental groups. Plasma DPP-4 activity in the mice in teneligliptin group 1 was significantly decreased 0.49 -fold, compared with that of mice in control group 1 ( $\mathrm{p}<0.05$; Fig. 3A). In addition, plasma DPP-4 activity in the mice in teneligliptin group 2 was significantly decreased 0.45 -fold, compared with that of mice in control group 2 ( $\mathrm{p}<0.05$; Fig. 3B).

Histological analysis. Hepatic steatosis was observed in all mice used in the experiment for the prevention of NAFLD in both control group 1 and teneligliptin group 1 ; however, severe hepatic steatosis was observed in control group 1 (Fig. 4A and Table III-A). Furthermore, a great amount of fatty droplets was observed in control group 1 , as shown by Oil Red O staining (Fig. 5A). The same degree of hepatic steatosis was 
Table II. Outcome of liver/body weight ratio and biochemical parameters in all mice in both types of experiments.

A, Outcome of liver/body weight ratio and biochemical parameters in mice in the experiment for NAFLD prevention

\begin{tabular}{lcc}
\hline Parameter & $\begin{array}{c}\text { Control } \\
\text { group 1 }\end{array}$ & $\begin{array}{c}\text { Teneligliptin } \\
\text { group 1 }\end{array}$ \\
\hline Liver/body weight ratio (\%) & $5.82 \pm 1.10$ & $5.80 \pm 0.98$ \\
AST (IU/l) & $293.88 \pm 93.28$ & $183.20 \pm 86.71^{\mathrm{a}}$ \\
ALT $(\mathrm{IU} / \mathrm{l})$ & $239.24 \pm 80.91$ & $150.76 \pm 81.99^{\mathrm{a}}$ \\
T-CHO (mg/dl) & $216.0 \pm 17.0126$ & $198.29 \pm 12.93^{\mathrm{a}}$ \\
Glucose $(\mathrm{mg} / \mathrm{dl})$ & $314.0 \pm 34.98$ & $264.33 \pm 31.63^{\mathrm{a}}$ \\
Insulin $(\mathrm{ng} / \mathrm{ml})$ & $3.91 \pm 3.59$ & $1.03 \pm 0.47^{\mathrm{a}}$ \\
GA $(\%)$ & $2.22 \pm 0.16$ & $1.72 \pm 0.62^{\mathrm{a}}$ \\
Hepatic TG $(\mathrm{mg} / \mathrm{dl})$ & $105.69 \pm 4.89$ & $86.85 \pm 6.61^{\mathrm{a}}$ \\
Hepatic FFA $(\mu \mathrm{Eq} / \mathrm{l})$ & $111.66 \pm 5.71$ & $82.81 \pm 3.93^{\mathrm{a}}$ \\
\hline
\end{tabular}

B, Outcome of liver/body weight ratio and biochemical parameters in mice in the experiment of the treatment of NAFLD

\begin{tabular}{lcc}
\hline Parameter & $\begin{array}{c}\text { Control } \\
\text { group 2 }\end{array}$ & $\begin{array}{c}\text { Teneligliptin } \\
\text { group 2 }\end{array}$ \\
\hline Liver/body weight ratio (\%) & $6.81 \pm 1.08$ & $6.80 \pm 1.08$ \\
AST (IU/l) & $140.09 \pm 61.53$ & $125.87 \pm 73.80$ \\
ALT (IU/l) & $121.03 \pm 52.21$ & $233.80 \pm 70.09^{\mathrm{b}}$ \\
T-CHO (mg/dl) & $227.88 \pm 16.97$ & $270.83 \pm 37.06^{\mathrm{b}}$ \\
Glucose $(\mathrm{mg} / \mathrm{dl})$ & $278.50 \pm 31.52$ & $313.38 \pm 44.14$ \\
Insulin $(\mathrm{ng} / \mathrm{ml})$ & $1.24 \pm 0.37$ & $1.16 \pm 0.38$ \\
GA $(\%)$ & $2.07 \pm 0.12$ & $1.50 \pm 0.71$ \\
Hepatic TG $(\mathrm{mg} / \mathrm{dl})$ & $107.71 \pm 5.62$ & $108.91 \pm 5.79$ \\
Hepatic FFA $(\mu \mathrm{Eq} / \mathrm{l})$ & $132.66 \pm 3.17$ & $134.18 \pm 3.92$ \\
\hline
\end{tabular}

${ }^{\mathrm{a}} \mathrm{p}<0.05$ vs. control group $1 ;{ }^{b} \mathrm{p}<0.05$ vs. control group 2 . NAFLD, non-alcoholic fatty liver disease; AST, aspartate aminotransferase; ALT, alanine aminotransferase; T-CHO, total-cholesterol; GA, glico albumin; TG, triglyceride; FFA, free fatty acid.

observed in all mice used in the experiment for the treatment of NAFLD (Fig. 4B and Table III-B). In addition, the same amount of fatty droplets was observed in both groups (Fig. 5B).

GTT. Mice in control group 1 exhibited glucose intolerance during a GTT, compared with those in teneligliptin group 1 (Fig. 6). Mice in teneligliptin group 1 exhibited a significant difference in insulin content during the GTT compared to the controls; however, mice in teneligliptin group 2 did not exhibit a significant difference in insulin content compared to their respective controls (Fig. 7).

Hepatic pro-inflammatory $m R N A$ expression. A previous study demonstrated that several pro-inflammatory cytokines are associated with the development of NASH (17). Since biochemical parameters, such as AST and ALT in the mice used in the experiment for the prevention of NAFLD differed
Table III. Histological findings of the liver in mice in both types of experiments.

A, Histological findings of the liver in mice in the experiment for NAFLD prevention

\begin{tabular}{lcc}
\hline Histological parameter & $\begin{array}{c}\text { Control } \\
\text { group 1 } \\
(\mathrm{n}=8)\end{array}$ & $\begin{array}{c}\text { Teneligliptin } \\
\text { group 1 } \\
(\mathrm{n}=8)\end{array}$ \\
\hline Hepatic steatosis & $8 / 8(100)$ & $8 / 8(100)$ \\
Grade 1 & $0(0)$ & $7(83.3)$ \\
Grade 2 & $6(83.3)$ & $1(16.7)$ \\
Grade 3 & $2((16.7)$ & $0(0)$ \\
Necroinflammation & $0 / 8(0)$ & $0 / 8(0)$ \\
Grade 1 & $0(0)$ & $0(0)$ \\
Grade 2 & $0(0)$ & $0(0)$ \\
Grade 3 & $0(0)$ & $0(0)$ \\
Ballooning degeneration & $0 / 8(0)$ & $0 / 8(0)$ \\
Fibrosis & $0 / 8(0)$ & $0 / 8(0)$ \\
\hline
\end{tabular}

$\mathrm{B}$, Histological findings of the liver in mice in the experiment for the treatment of NAFLD

\begin{tabular}{lcc}
\hline Histological parameter & $\begin{array}{c}\text { Control } \\
\text { group 2 } \\
(\mathrm{n}=8)\end{array}$ & $\begin{array}{c}\text { Teneligliptin } \\
\text { group 2 } \\
(\mathrm{n}=8)\end{array}$ \\
\hline Hepatic steatosis & $8 / 8(100)$ & $8 / 8(100)$ \\
Grade 1 & $0(0)$ & $0(0)$ \\
Grade 2 & $3(37.5)$ & $4(50.0)$ \\
Grade 3 & $5(62.5)$ & $4(50.0)$ \\
Necroinflammation & $0 / 8(0)$ & $0 / 8(0)$ \\
Grade 1 & $0(0)$ & $0(0)$ \\
Grade 2 & $0(0)$ & $0(0)$ \\
Grade 3 & $0(0)$ & $0(0)$ \\
Ballooning degeneration & $0 / 8(0)$ & $0 / 8(0)$ \\
Fibrosis & $0 / 8(0)$ & $0 / 8(0)$ \\
\hline
\end{tabular}

The numbers are expressed as the number of animals and percentage. NAFLD, non-alcoholic fatty liver disease.

significantly between the two groups, we examined the relative expression levels of hepatic pro-inflammatory cytokines. The mRNA expression levels of tumor necrosis factor (TNF)- $\alpha$, interferon (IFN) $-\gamma$, interleukin (IL)- $1 \beta$ and IL- 6 were significantly decreased in teligliptin group 1 (respectively, $\mathrm{p}<0.05$ ) (Fig. 8A). On the other hand, the ALT levels in the mice used in the experiment for the treatment of NAFLD was significantly increased in teneligliptin group 2 (Table II-B). As expected, the expression levels of TNF- $\alpha$ and IL- 6 were also significantly increased in the mice in teneligliptin group 2 (Fig. 8B). However, the mRNA expression levels of IL-1 $\beta$ were significantly decreased in the mice in teneligliptin group 2, while the levels of IFN- $\gamma$ exhibited no significant difference (Fig. 8B). 

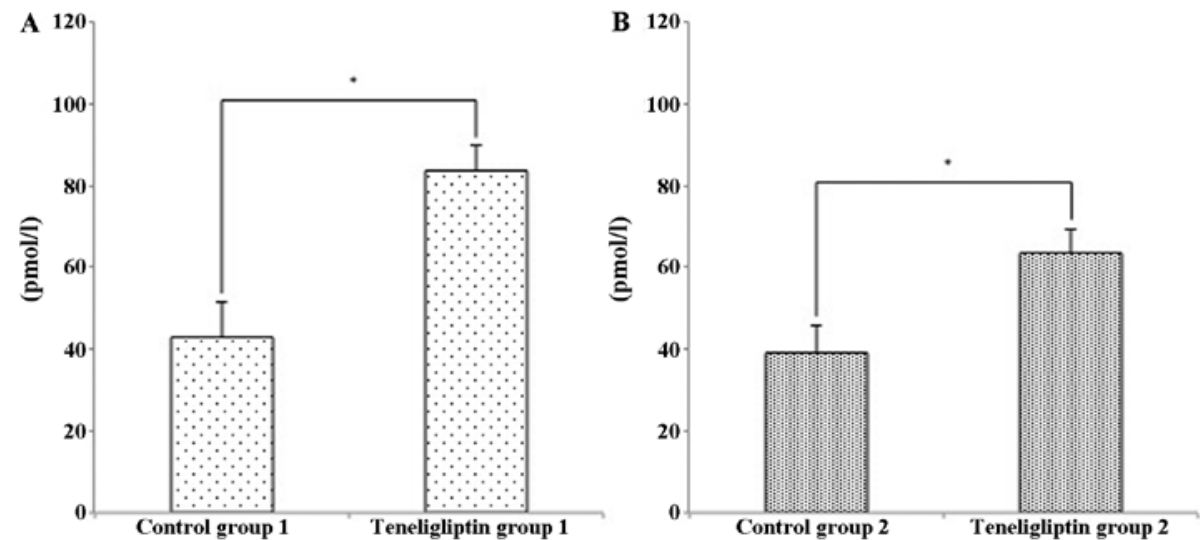

Figure 2. (A) Levels of plasma glucagon-like peptide-1 (GLP-1) concentration between control group 1 and teneligliptin group 1. There was a significant difference in the of plasma concentration of GLP-1 between the two groups. ${ }^{*} \mathrm{p}<0.05$ vs. control group 1. (B) Levels of plasma GLP-1 concentration between control group 2 and teneligliptin group 2 . There was a significant difference in the concentration between the two groups. "p $<0.05$ vs. control group 2.
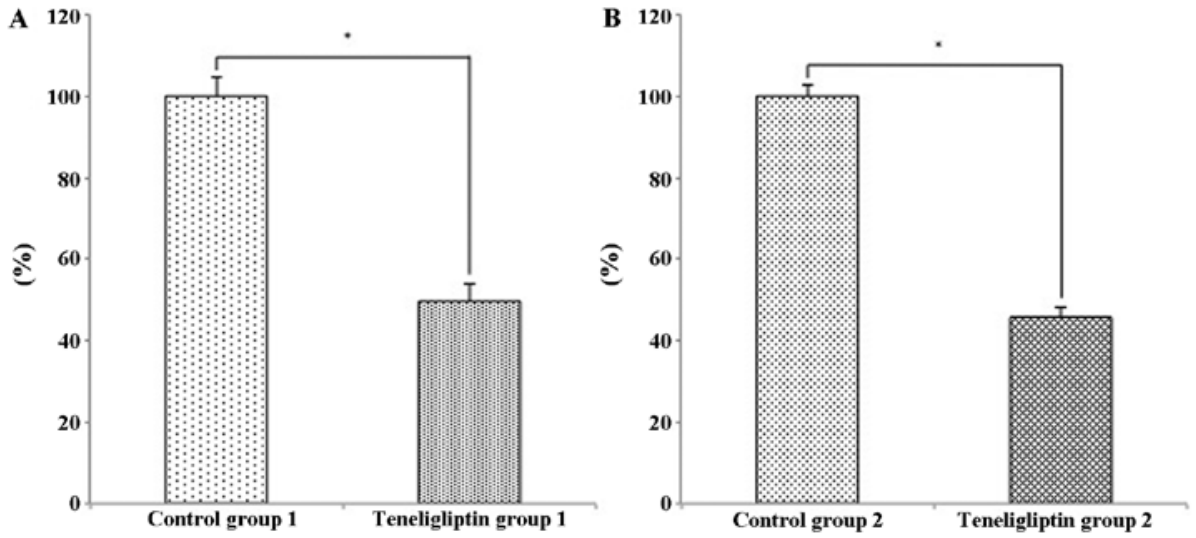

Figure 3. (A) Dipeptidyl peptidase-4 (DPP-4) activity between control group 1 and teneligliptin group 1 . There was a significant difference in the levels of plasma activity between the two groups. "p $<0.05$ vs. control group 1. (B) DPP-4 activity between control group 2 and teneligliptin group 2 . There was a significant difference in the levels of plasma activity between the two groups. " $\mathrm{p}<0.05$ vs. control group 2.
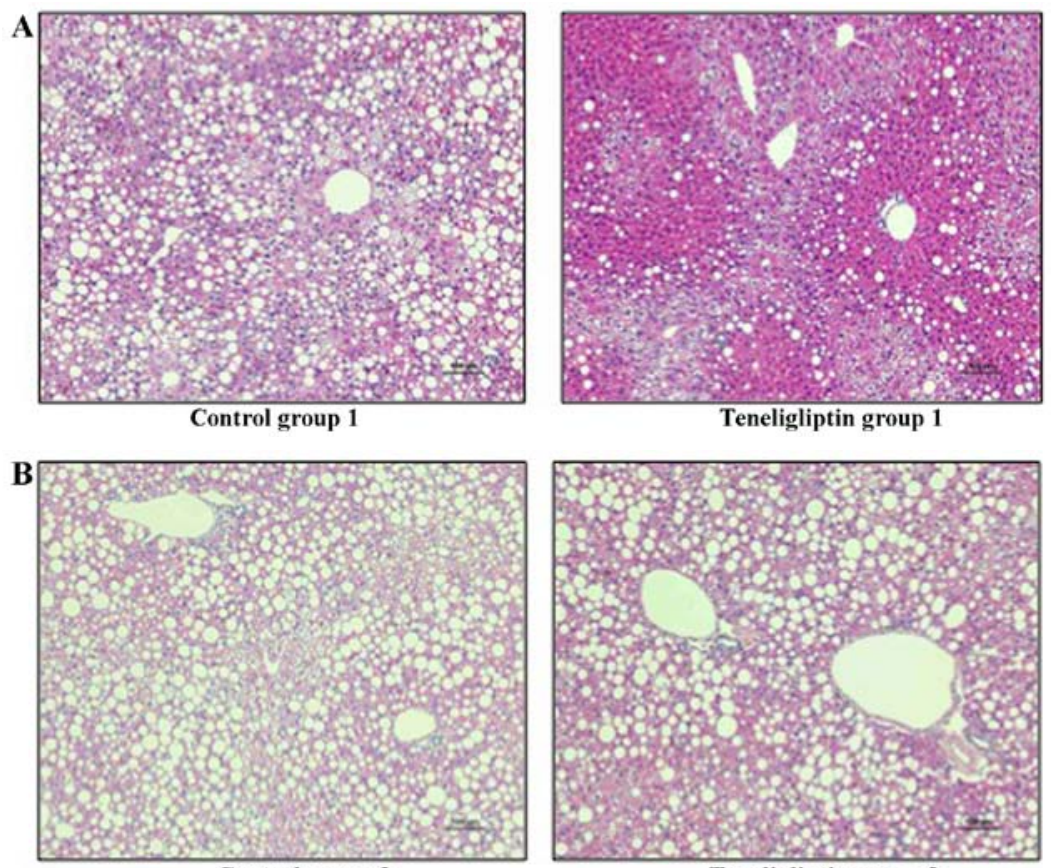

Control group 2

Teneligliptin group 2

Figure 4. (A) Histological analysis by hematoxylin and eosin staining in all mice in the experiment for the prevention of non-alcoholic fatty liver disease (NAFLD). Severe fatty droplets were observed in livers of mice in control group 1, as compared with the livers of mice in teneligliptin group 1. (B) Histological analysis by hematoxylin and eosin staining in all mice in the experiment for the treatment of NAFLD. Same degree of fatty droplets was observed in the livers from mice in the two groups. 

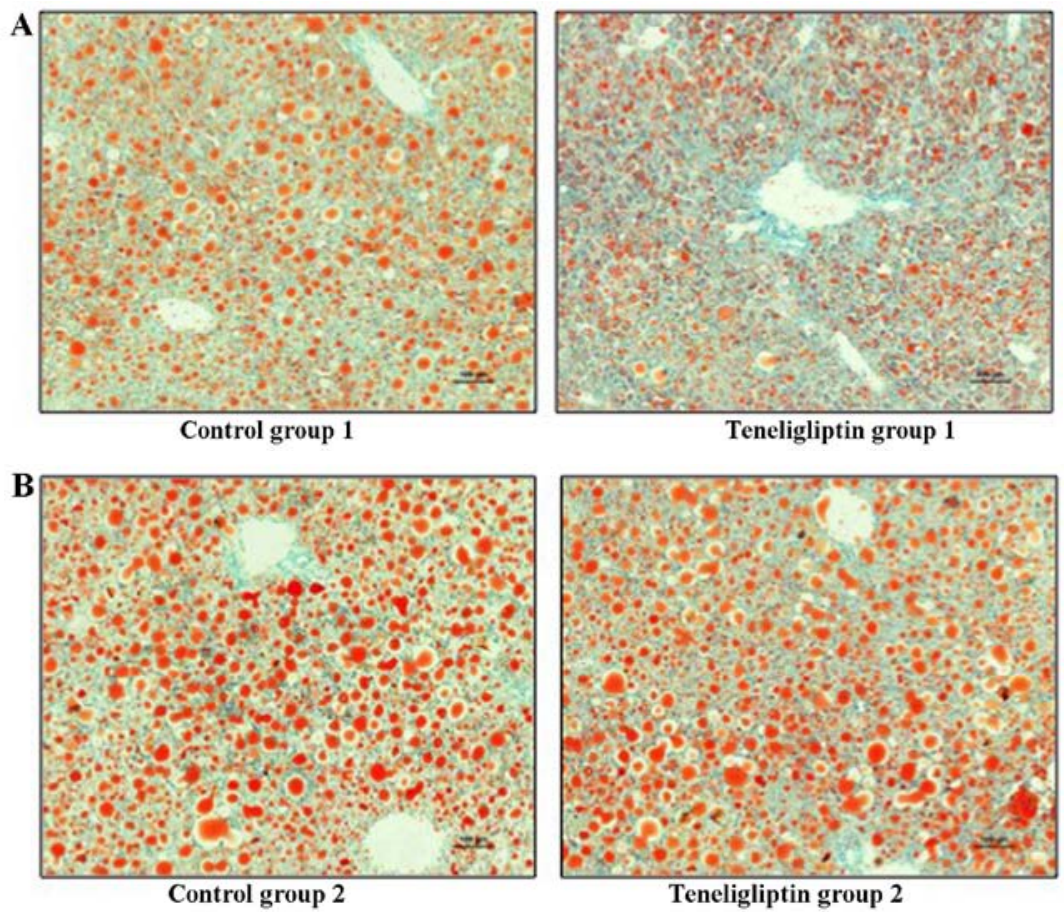

Figure 5. (A) Histological analysis by Oil Red O staining in all mice in the experiment for the prevention of non-alcoholic fatty liver disease (NAFLD). A lot of large fatty droplets were observed in livers of the control group 2, as compared with the livers of the teneligliptin group 2. (B) Histological analysis by Oil Red O staining in all mice in the experiment for the treatment of NAFLD. Same degree in a lot of large fatty droplets was observed in livers of mice in the two groups.
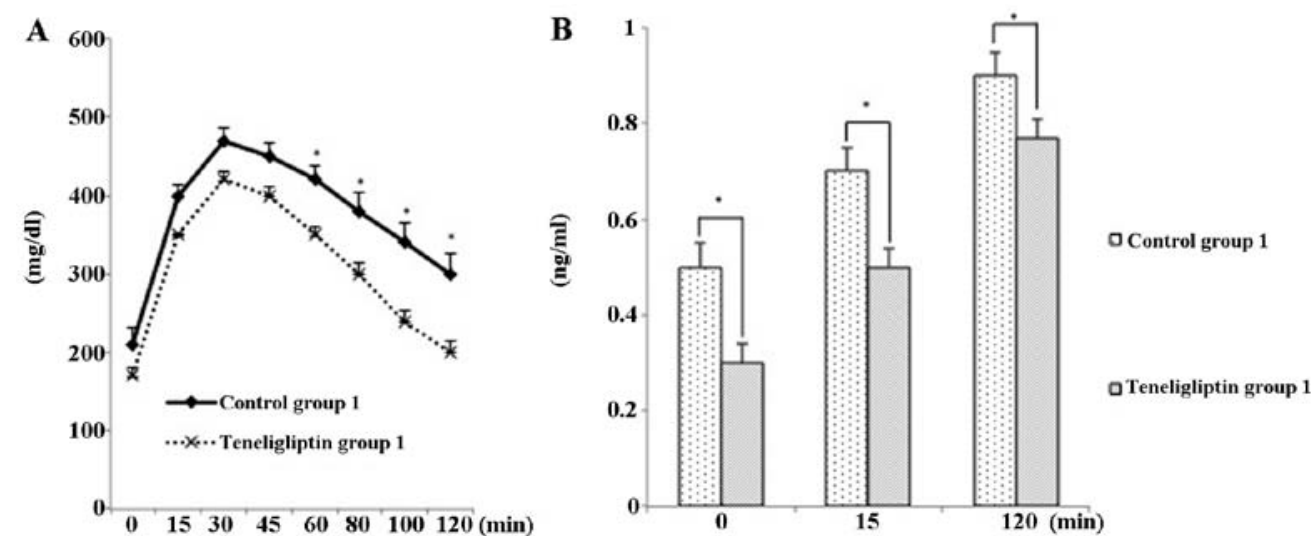

Figure 6. (A) Glucose tolerance test (GTT) assay was performed in 9-week-old mice of experiment of prevention for non-alcoholic fatty liver disease (NAFLD) (n=5 pairs). Mice in teneligliptin group 1 exhibited glucose intolerance during a GTT. " $\mathrm{p}<0.05$ vs. control group 1. (B) The corresponding blood insulin level during GTT time course was determined ( $\mathrm{n}=5$ pairs successfully examined by GTT assay). Teneligliptin group 1 exhibited a significant difference in insulin content during the GTT. $\mathrm{p}<0.05$ vs. control group 1.
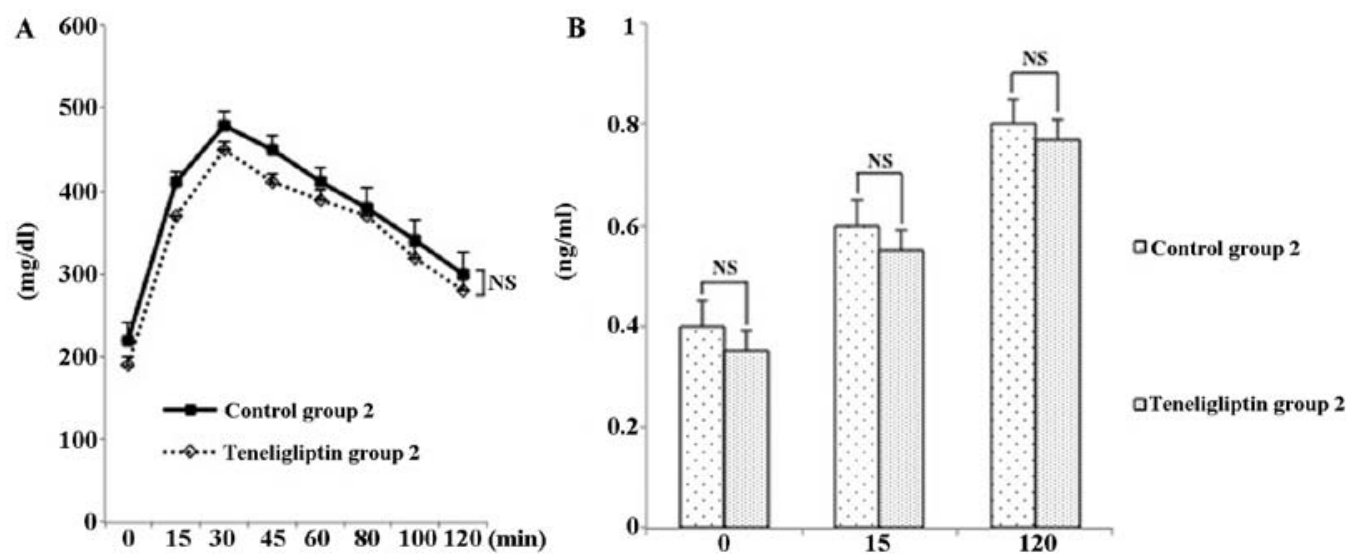

Figure 7. (A) Glucose tolerance test (GTT) assay was performed in 13-weeks-old mice of experiment of treatment for non-alcoholic fatty liver disease (NAFLD) $(\mathrm{n}=5$ pairs). There was no significant difference in glucose intolerance during a GTT. (B) The corresponding blood insulin level during GTT time course was determined ( $\mathrm{n}=5$ pairs successfully examined by GTT assay). There was no significant difference in insulin content during a GTT. NS, no significant difference. 

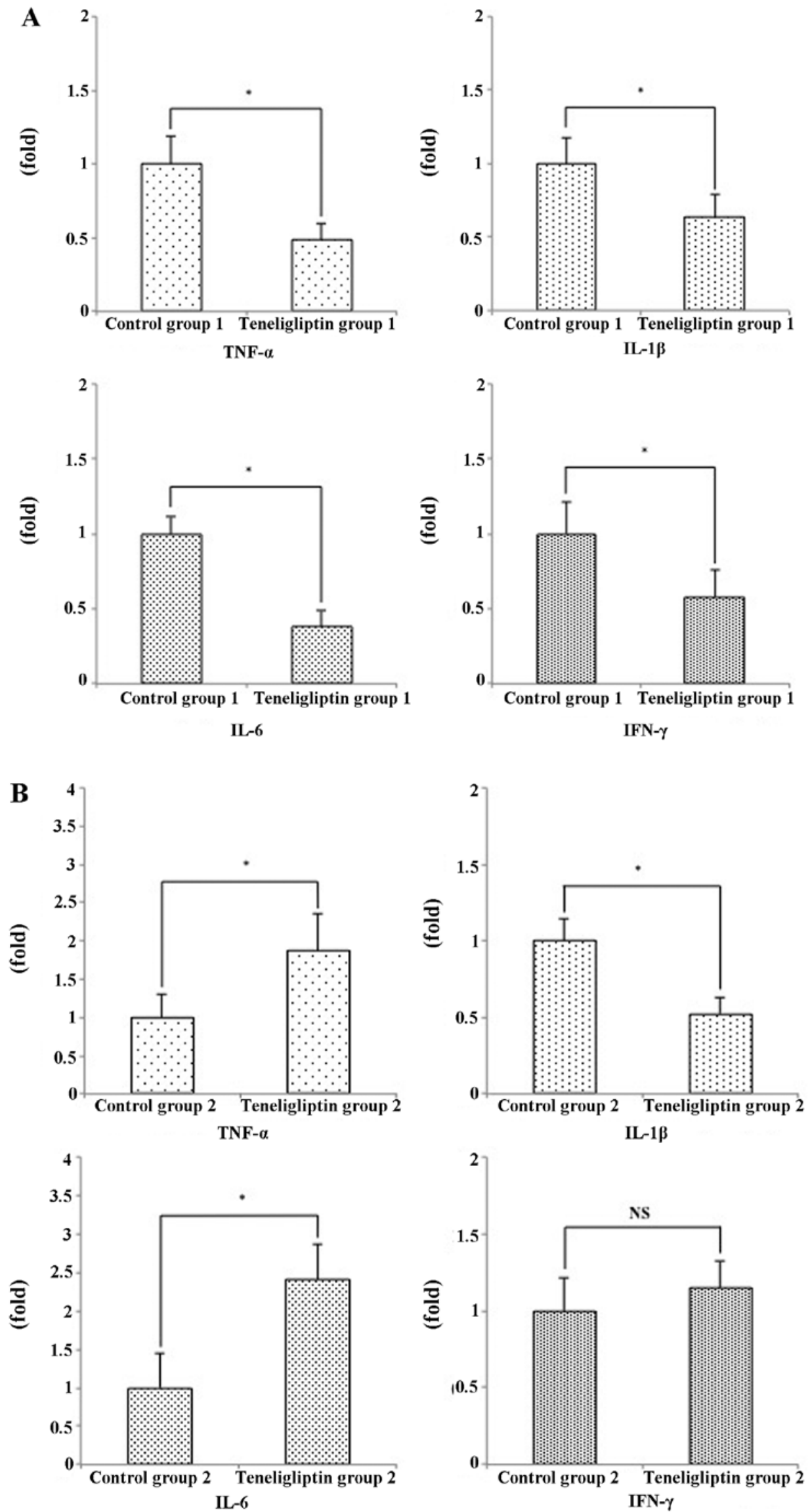

Figure 8. (A) Relative hepatic mRNA expression levels of pro-inflammatory cytokines in the experiment for the prevention of non-alcoholic fatty liver disease (NAFLD). There was a significant difference in the expression levels of these pro-inflammatory cytokines such as tumor necrosis factor- $\alpha$ (TNF- $\alpha$ ), interleukin (IL), IL-6 and interferon- $\gamma$ (IFN- $\gamma$ ) between the two groups. " $\mathrm{p}<0.05$ vs. control group 1. (B) Relative hepatic mRNA expressions of pro-inflammatory cytokines in the experiment for treatment of NAFLD. There was a significant difference in the expression levels of these pro-inflammatory cytokines such as TNF- $\alpha$, IL-1 $\beta$ and IL- 6 between the two groups. "p $<0.05$ vs. control group 2. 
Hepatic lipogenic-related $m R N A$ expression. The differences in the histological findings and hepatic TG content observed between the mice used in the experiment for the prevention of NAFLD and those used in the experiment for the treatment of NAFLD suggest that the expression of cytokines is involved in the development of NAFLD. The expression of lipogenic enzymes is mainly regulated at the transcriptional level in a hyperinsulinemic and hyperglycemic state. Sterol regulatory element binding protein-1c (SREBP-1c) and carbohydrate response element binding protein (ChREBP), are well known to be involved in these states (18). The induction of lipogenic genes, such as fatty acid synthase (FAS) is under the concerned action of ChREBP and of the transcription factor SREBP-1c in response to glucose and insulin (18). In particular, the expression of SREBP-1c is stimulated by insulin $(19,20)$. In addition to FAS, stearoyl-CoA desaturase-1 (SCD-1) may be critical to the role of triglyceride accumulation in hepatocytes (21). Peroxisome proliferator-activated receptors (PPARs) are nuclear transcription factors that include three subtypes: $\alpha, \beta$ and $\gamma$. PPAR $-\gamma$ agonists, such as thiazolidinediones improve insulin action in peripheral tissues and are effective in the treatment of patients with NAFLD (22). Unlike PPAR- $\gamma$, PPAR- $\alpha$ mediates the expression of genes that regulate lipid oxidation (23). PPAR- $\alpha$ agonists, such as fibrates, have been used in the treatment of hypertriglyceridemia and to reduce cardiovascular risk (24).

In the present study, the hepatic TG content in the teneligliptin group 1 was reduced, compared with that in control group 1 (Table II-A). On the other hand, there was no significant difference in the hepatic TG between control group 2 and teneligliptin group 2 (Table II-B). These results coincided with the result that the relative mRNA expression levels of SREBP-1c and ChREBP were reduced in teneligliptin group 1, but were not reduced in teneligliptin group 2 compared with control group 2 (Fig. 9). On the other hand, the mRNA expression levels of FAS were significantly decreased in teneligliptin group 1 (Fig. 9A); however, there was no significant difference in the mRNA expression levels of SCD-1 between control group 2 and teneligliptin group 2 (Fig. 9B). In addition, the expression of PPAR- $\alpha$, a key element in the $\beta$-oxidation of FFAs, differed significantly between control group 1 and teneligliptin group (Fig. 9A). However, the expression of PPAR- $\alpha$ in control group 2 and teneligliptin group 2 did not exhibit a significant difference (Fig. 9B). The mRNA expressions of PPAR- $\gamma$ was below the lower limit of detection in all groups (data not shown).

Hepatic steatosis develops as result of abnormally enhanced de novo lipid synthesis and fat delivery (25). ATP-citrate lyase (ACL) is an important lipogenic enzyme that regulates the flow of glucose carbons to cytosolic acetylcoenzyme A (CoA) (26). Acetyl-CoA carboxylase (ACC) is a biotinylated enzyme that catalyzes the ATP-dependent carboxylation of acetyl-CoA to produce malonyl-CoA. Animals have two ACC genes (ACC1 and ACC2). In particular, ACC1 is a protein that is mainly expressed in liver and adipose tissue (27). The phosphorylation of ACC by AMP-activated protein kinase (AMPK) results in its inactivation and inability to inhibit carnitine palmitoyltransferase-1 (CPT-1). CPT-1 is responsible for fatty acid transport into the mitochondria. The liver isoform (CPT1A) is localized in the outer mitochondrial membrane and exposes its active site at the cytosolic face of the mitochondrion (28). Insulin can regulate the sensitivity of CPT1A for malonyl-CoA in the liver (29). In this study, we examined the relative expression levels of these hepatic lipogenic-related enzymes. Against our prediction, the expression levels of ACC1 were significantly decreased in teneligliptin group 1 (Fig. 10A), but were significantly increased in teneligliptin group 2 (Fig. 10B). Furthermore, the expression levels of ACL were significantly increased in teneligliptin group 1 (Fig. 10A); however these expression levels were significantly decreased in teneligliptin group 2 (Fig. 10B). In addition, the expression levels of CPT1A were significantly decreased in teneligliptin group 1; however, the expression levels of CPT1A were not significantly different between control group 2 and teneligliptin group 2 (Fig. 10B).

Mitochondrial oxidation of FFA-related mRNA expression. It is known that once the fatty acid is inside the mitochondrial matrix, $\beta$-oxidation can then begin. It has 4 steps (30). First, acyl-CoA is oxidized by acyl-CoA dehydrogenase to yield a trans-2-enoyl-CoA. This step is followed by hydratation of the double bond. The resulting L-3-hydroxy-acyl-CoA is again oxidized into 3-keto-acyl-CoA in the third step. Finally, the thiolytic cleavage of 3-keto-acyl-CoA produces a 2-carbon chain-shortened acyl-CoA plus acetyl-CoA. In this study, we examined the expression of mitochondrial oxidation of fatty acid-related genes, such as medium-chain acyl-CoA dehydrogenase (MCAD), long-chain acyl-CoA dehydrogenase (LCAD), enoyl-CoA hydratase (ECAH), 3-hydroxyacyl-CoA dehydrogenase (HACDH) and 3-ketoacyl-CoA thiolase (bKACTB). The relative expression levels of these genes, such as MCAD, LCAD, ECAH, HACDH and bKACTB were not significantly different between control group 1 and teneligliptin group 1 (Fig. 11A). In addition, the expression levels of these same genes were not significantly different between control group 2 and teneligliptin group 2 (Fig. 11B).

Insulin resistance-related $m R N A$ expression. Insulin signaling is initiated when insulin binds to its receptor expressed on the cell membrane. The insulin receptor is a receptor tyrosine kinase upon the binding of insulin, is autophosphorylated and activated. Once activated, the receptor can phosphorylate tyrosine residues on the insulin receptor substrate (IRS) molecules. IRS proteins bind the phosphatidylinositol-3-kinase (PI3K) and activate it. PI3K eventually leads to many of the effects of insulin on glucose, lipid and protein metabolism. IRS-1 and IRS-2 exhibit high structural homology, are abundantly expressed in the liver. In addition, AMPK promotes glucose uptake into skeletal muscle and suppresses glucose output from the liver via insulin-independent mechanisms (31). These receptors are thought to be responsible for transducing insulin signals from the insulin receptor to the intracellular effectors in the regulation of glucose and lipid homeostasis $(32,33)$. IRS-2 mainly functions during the fasting state and immediately after re-feeding, while IRS-1 functions primarily after re-feeding (34). Moreover, IRS-1 has been observed to play a dominant role under states of nutrient excess (35). In this study, the relative expression levels of these genes, such as PI3K, IRS-1, IRS-2 and AMPK were significantly different between teneligliptin group 1 and control group 1 (Fig. 12A). 


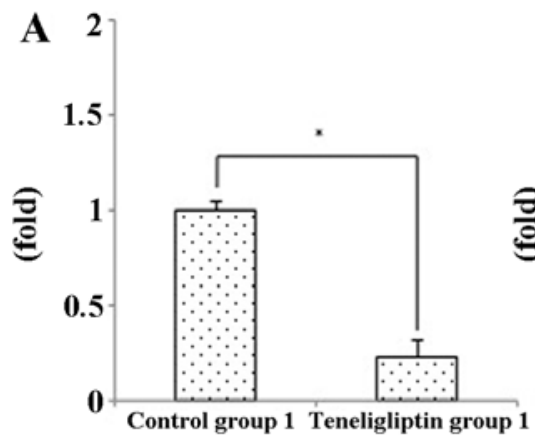

SREBP-1c

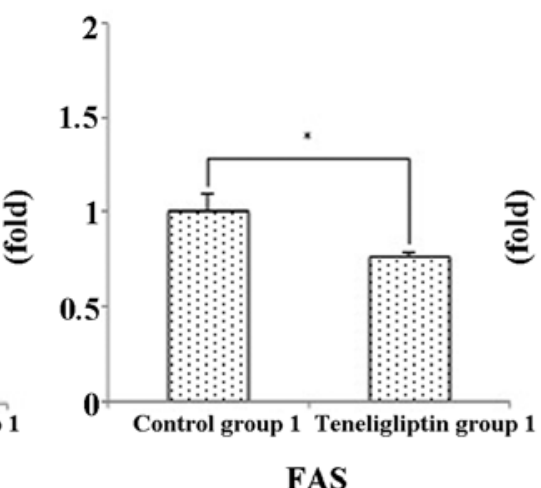

FAS

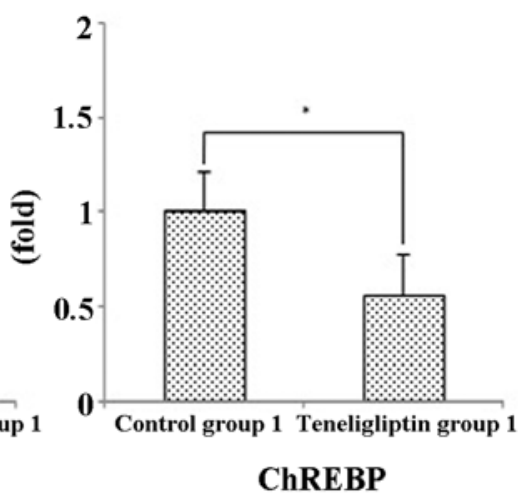

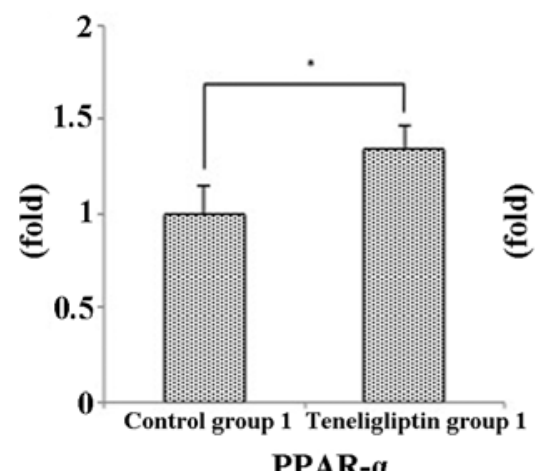

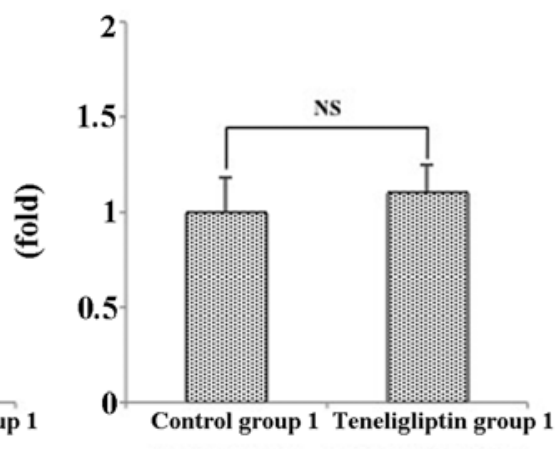

SCD-1

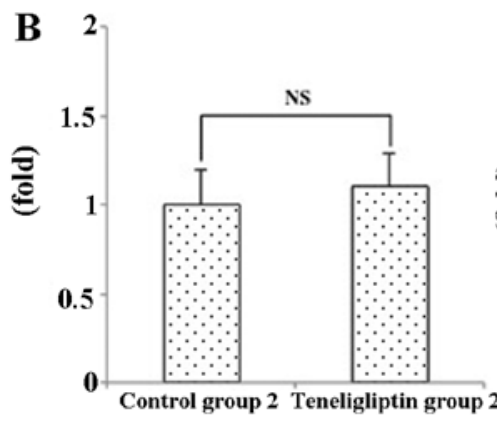

SREBP-1c

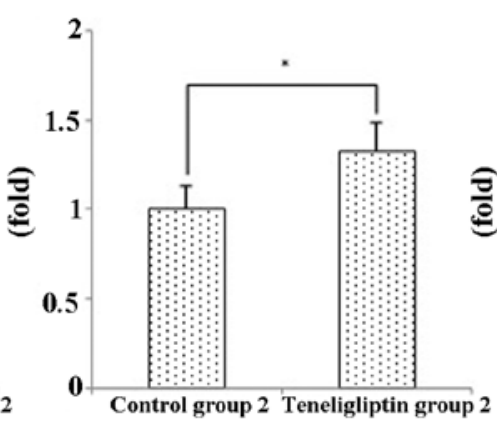

FAS

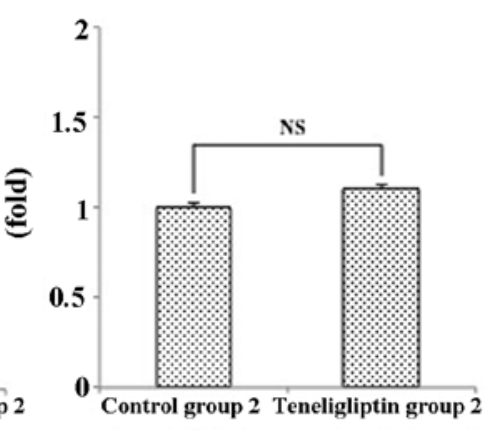

ChREBP

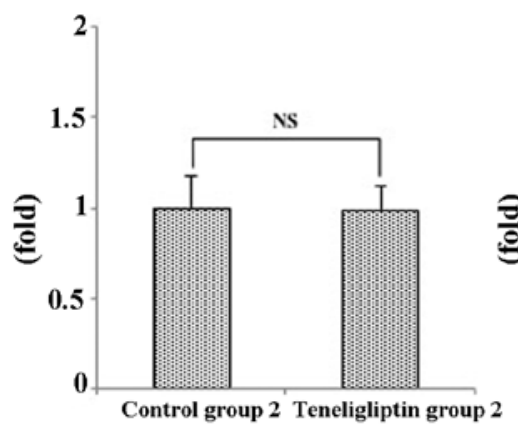

PPAR- $\alpha$

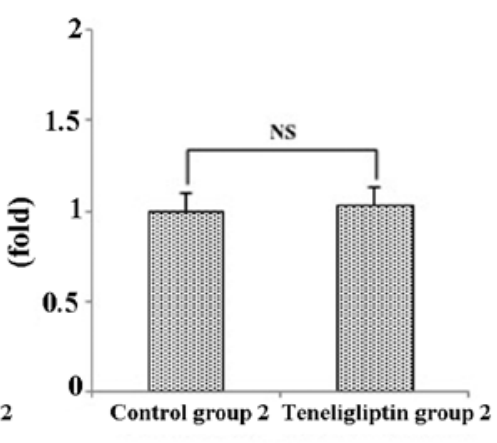

SCD-1

Figure 9. (A) Relative hepatic mRNA expression levels of lipogenic-related genes in the experiment for the prevention of non-alcoholic fatty liver disease (NAFLD). There was a significant difference in the expression of these lipogenic-related genes such as sterol regulatory element binding protein-1c (SREBP-1c), FAS and carbohydrate response element binding protein (ChREBP) between the two groups. In addition, the hepatic expression of peroxisome proliferator-activated receptor- $\alpha$ (PPAR- $\alpha$ ) was increased in teneligliptin group 1. However, there was no significant difference in the expression of stearoyl-CoA desaturase-1 (SCD-1) between the two groups. ${ }^{*} \mathrm{p}<0.05 \mathrm{vs}$. control group 1. (B) Relative hepatic mRNA expression levels of lipogenic-related genes in the experiment for the treatment of NAFLD. There was no significant difference in the expression of SREBP-1c, ChREBP, PPAR- $\alpha$ and SCD-1 between the two groups. * $<0.05$ vs. control group 2. NS, no significant difference.

However, the expression levels of PI3K and AMPK were not significantly different between control group 2 and teneligliptin group 2 (Fig. 12B). The levels of IRS-1 and IRS-2 were significantly decreased in teneligliptin group 2 compared 


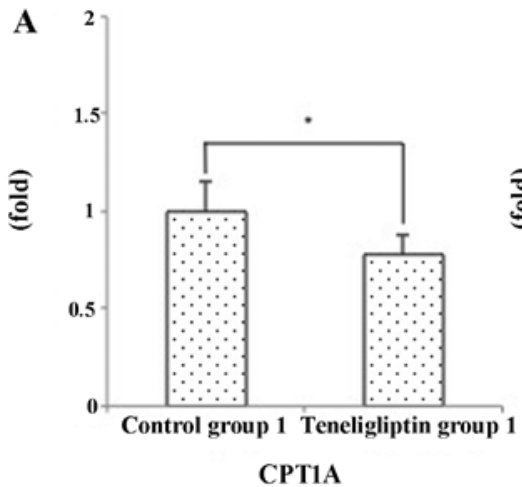

CPT1A

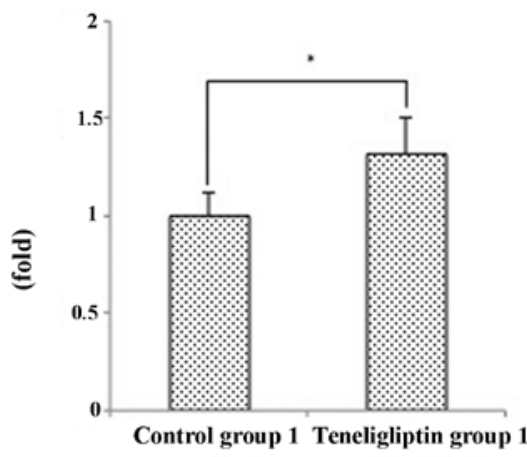

ACL
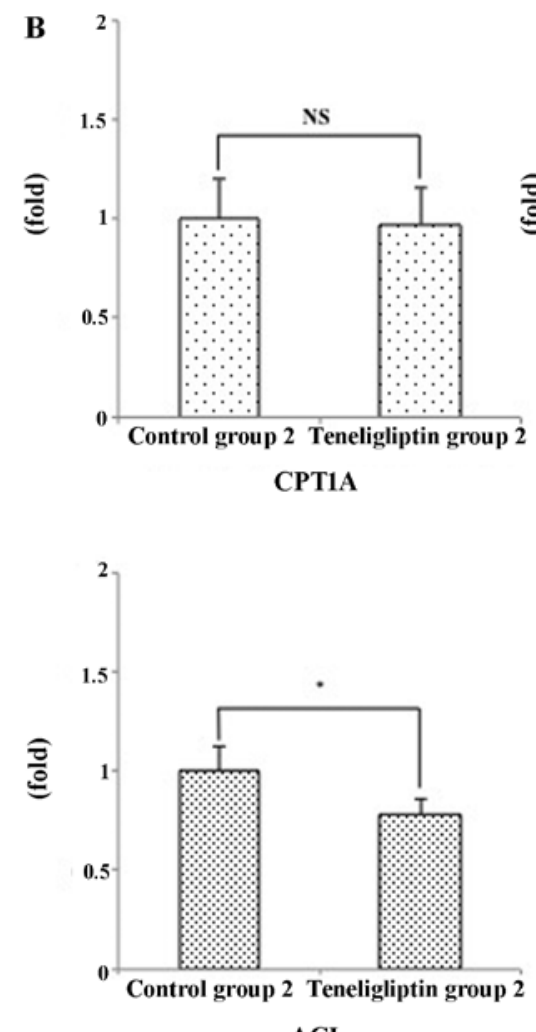

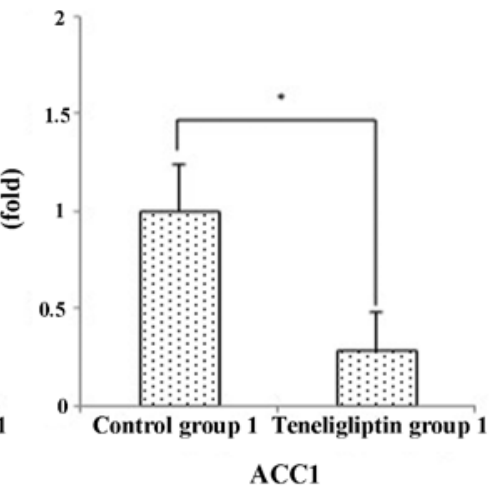

$\mathrm{ACC} 1$

ACL

Figure 10. (A) Relative hepatic mRNA expression levels of $\beta$-oxidation-related genes in the experiment for the prevention of non-alcoholic fatty liver disease (NAFLD). There was a significant difference in the expression of these $\beta$-oxidation-related genes such as carnitine palmitoyltransferase-1 (CPT1), acetyl-CoA carboxylase (ACC)1, and ATP-citrate lyase (ACL) between the two groups. "p $<0.05$ vs. control group 1. (B) Relative hepatic mRNA expressions of $\beta$-oxidationrelated genes in the experiment for the treatment of NAFLD. There was a significant difference in the expression of these $\beta$-oxidation-related genes, such as $\mathrm{ACC} 1$ and ACL between the two groups. "p $<0.05$ vs. control group 2. NS, no significant difference.

to control group 2 (Fig. 12B). In addition, gluconeogenic genes, such as phosphoenolpyruvate carboxykinase (PEPCK) and glucose-6-phosphatase (G6Pase) contribute to insulin resistance and glucose intolerance (36). In this study, the 

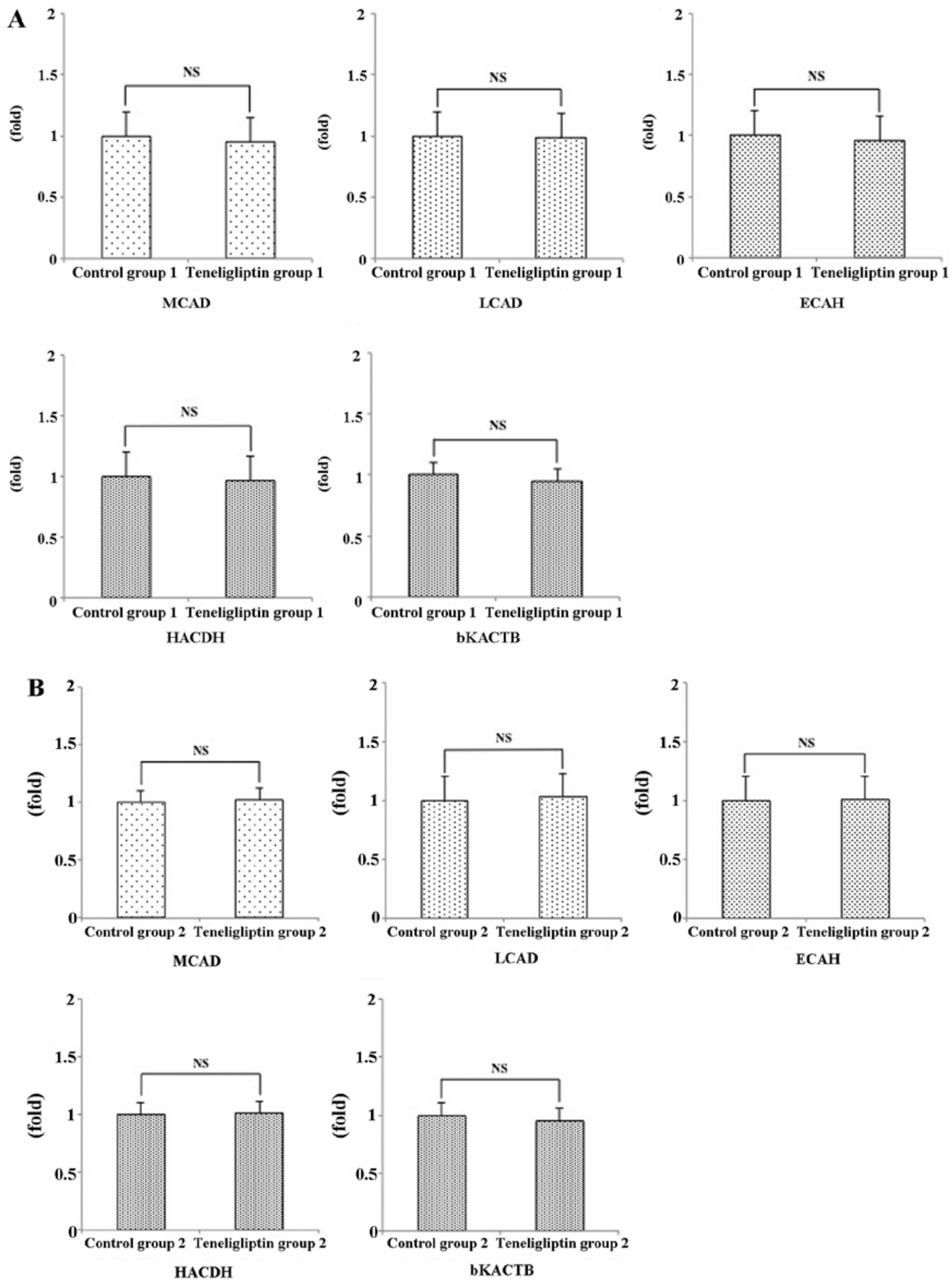

Figure 11. (A) Relative hepatic mRNA expression levels of mitochondrial $\beta$-oxidation-related genes in the experiment for the prevention of non-alcoholic fatty liver disease (NAFLD). There was no significant difference in the expression levels of these mitochondrial $\beta$-oxidation-related genes such as medium-chain acylCoA dehydrogenase (MCAD), long-chain acyl-CoA dehydrogenase (LCAD), enoyl-CoA hydratase (ECAH), 3-hydroxyacyl-CoA dehydrogenase (HACDH) and 3-ketoacyl-CoA thiolase (bKACTB) between the two groups. (B) Relative hepatic mRNA expression levels of mitochondrial $\beta$-oxidation-related genes in the experiment for the treatment of NAFLD. There was no significant difference in the expression levels of these mitochondrial $\beta$-oxidation-related genes such as MCAD, LCAD, ECAH, HACDH and bKACTB between the two groups. NS, no significant difference.

relative expression levels of PEPCK and G6Pase were not significantly different between control group 1 and teneligliptin group 1 (Fig. 12A); however, these expression levels were significantly increased in teneligliptin group 2 compared to control group 2 (Fig. 12B).

\section{Discussion}

There are many patients with NAFLD associated with T2DM and obesity. In the present study, we fed ob/ob mice, animal models of the disease, a HCD containing fructose as a main 


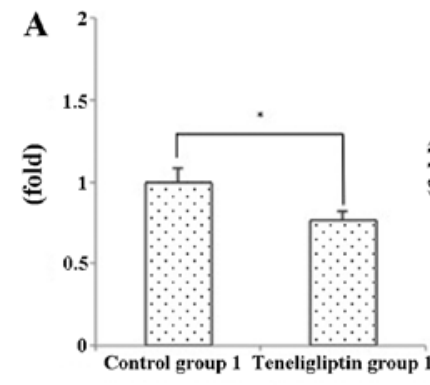

PI3K
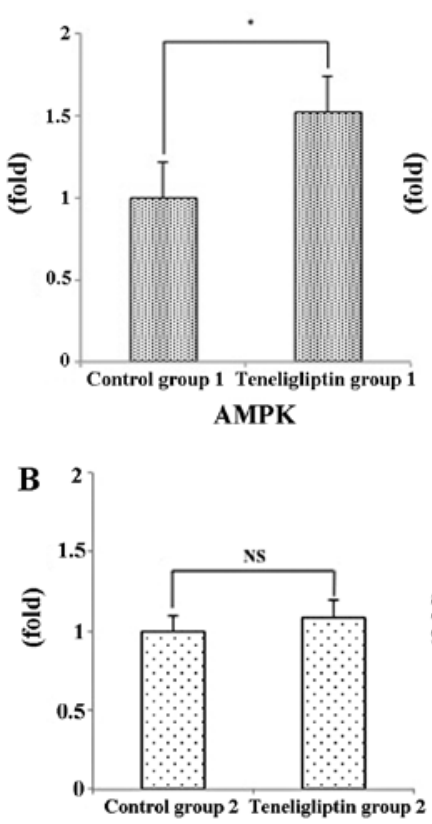

PI3K

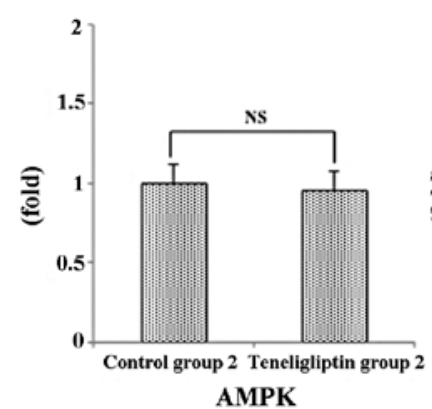

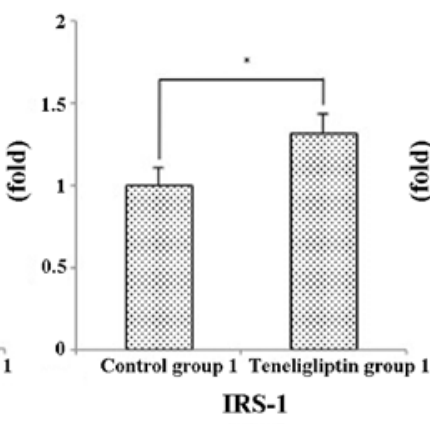
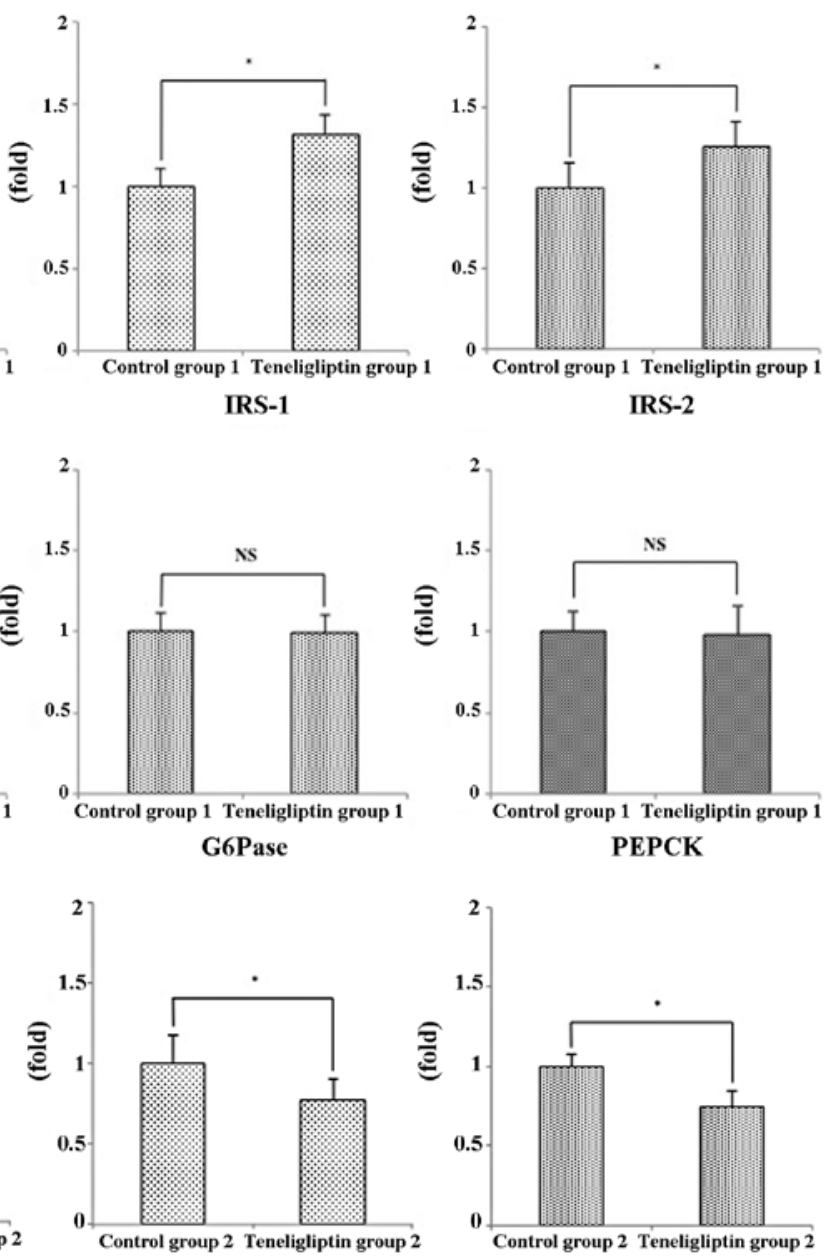

IRS-1
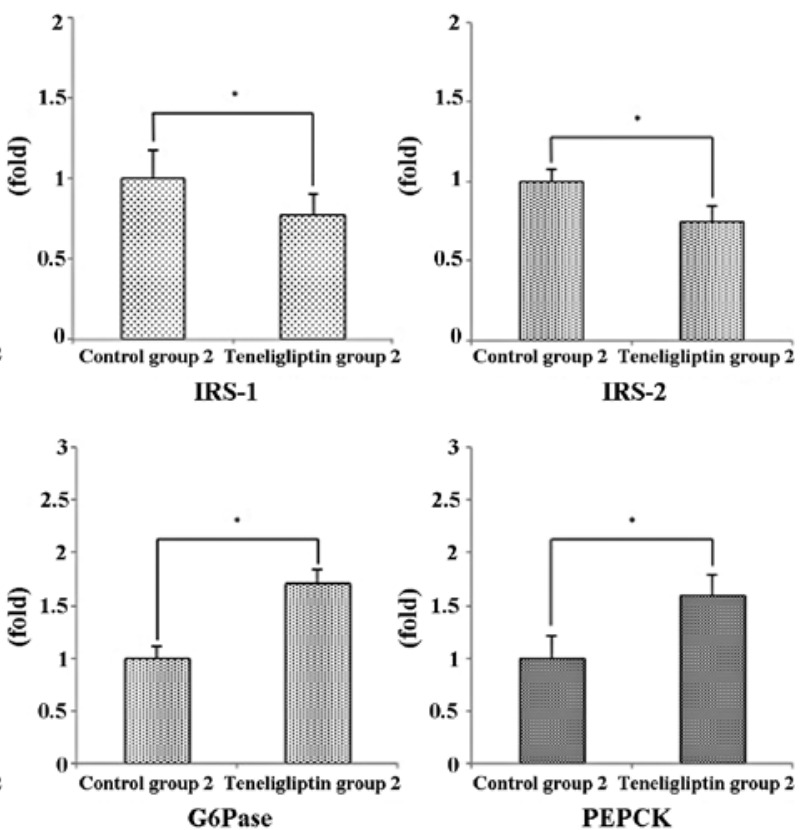

Figure 12. (A) Relative hepatic mRNA expression levels of insulin resistance-related genes in the experiment for the prevention of non-alcoholic fatty liver disease (NAFLD). There was a significant difference in the expression of these insulin signaling genes such as phosphatidylinositol-3-kinase (PI3K), insulin receptor substrate-1 (IRS-1), IRS-2 and AMP-activated protein kinase (AMPK) between the two groups. There was no significant difference in the expression of these gluconeogenic genes such as PEPCK and glucose-6-phosphatase (G6Pase) between the two groups. *p<0.05 vs. control group 1. (B) Relative hepatic mRNA expression levels of insulin signaling-related genes in the experiment for the prevention of NAFLD. There was a significant difference in the expression of these insulin signaling-related genes such as IRS-1 and IRS-2 between the two groups. There was no significant difference in the expression of these gluconeogenic genes such as PEPCK and G6Pase between the two groups. "p $<0.05$ vs. control group 2. NS, no significant difference.

component to evaluate the efficacy of teneligliptin, a diabetes drug, for the treatment of HCD-induced NAFLD.

In the experiment for the prevention of NAFLD, a comparison of mice fed the HCD supplemented with teneligliptin from the initial stage of the study with mice fed the HCD alone revealed no significant difference in weight gain between the two groups. However, histological finding in the liver revealed that the occurrence of hepatic steatosis was suppressed in the mice fed the HCD supplemented with teneligliptin. In the following experiment for the treatment of NAFLD, we compared mice fed the HCD supplemented with teneligliptin after the occurrence of a certain degree of steatosis with the mice continuously fed HCD alone. The results revealed no significant difference in weight gain between the two groups, and a similar degree of steatosis was observed in both groups. In addition, our results revealed that the plasma level of GLP-1 was significantly increased in both teneligliptin groups. Furthermore, both teneligliptin groups exhibited the same degree of DPP-4 activity. Therefore, we examined whether some factors, apart from GLP-1 and DPP-4 activity, are 
associated with these histological changes. To investigate the mechanism contributing to the differences in histological findings observed between these two experiments, we measured plasma parameters related to both hepatic disorders and lipids and the hepatic TG levels, which were likely to yield some differences. The results revealed a decrease in the plasma AST and ALT levels, the parameters indicative of hepatic disorder, in the mice fed the teneligliptin-supplemented HCD from the initial stage of the study. In addition, decreased liver TG levels, which are hallmarks of steatosis, were observed in the mice fed the teneligliptin-supplemented HCD from the initial stage of the study. The plasma glucose and insulin levels were also decreased in these mice. In the mice fed the HCD supplemented with teneligliptin after the occurrence of steatosis, the ALT levels increased, and no significant difference was observed in the plasma glucose and insulin levels between the two groups. In contrast to the mice between control group 1 and teneligliptin group 1, the mice in teneligliptin group 2 did not exhibit a significant difference in glucose tolerance and insulin content during the GTT between control group 2 and teneligliptin group 2 . These results indicate that teneligliptin does not always improve insulin resistance. These biochemistry results were mostly consistent with the histological findings.

Most importantly, the T2DM drug, teneligliptin, showed resistance to the occurrence of hepatic steatosis induced by a diet containing fructose as a main component when the diet was fed from the initial stage of the study, but the drug exerted a poor therapeutic effect, as determined by histological analysis, in the presence of a certain degree of steatosis. To elucidate the mechanisms behind these results, we examined the liver expression of genes associated with the progression of NAFLD, various lipid-related genes including factors related to mitochondrial $\beta$-oxidation, and genes associated with insulin resistance. A comparison of the liver expression of pro-inflammatory cytokines (TNF- $\alpha$, IL- 6 , IL-1 $\beta$ and IFN- $\gamma$ ) revealed the decreased expression of these cytokines in the mice used in the experiment for the prevention of NAFLD. By contrast, the expression of TNF- $\alpha$ and IL- 6 increased in the mice used in the experiment for the treatment of NAFLD. Next, the expression of lipid synthesis-related genes, such as SREBP-1c, FAS and ChREBP was decreased in the mice used in the experiment for the prevention of NAFLD. By contrast, the expression of FAS increased in the mice used in the experiment for the treatment of NAFLD. These results were consistent with the histological findings. We further studied genes associated with fatty acid oxidation and mitochondrial $\beta$-oxidation. The expression of CPT1A and ACC1 decreased and the expression of ACL increased in the mice used in the experiment for the prevention of NAFLD. In the mice fed the diet after the occurrence of steatosis, however, the expression of CPT1A did not differ significantly from that of the controls, but the expression of $\mathrm{ACC} 1$ increased while and the expression of ACL decreased. As for the expression of factors associated with other stages of $\beta$-oxidation, the expression of PPAR- $\alpha$ increased in the mice used in the experiment for the prevention of NAFLD. These results suggest that the early administration of teneligliptin also affects fatty acid oxidation.

We also examined the insulin resistance associated with the occurrence of NAFLD. The biochemistry and GTT results suggested that the early administration of teneligliptin improved insulin resistance. Determining the expression of genes associated with insulin signaling, the expression of IRS-1 and AMPK increased and the expression of PI3K decreased in the mice of the experiment for prevention of NAFLD. In the mice fed the teneligliptin-supplemented diet after the occurrence of steatosis. However, the expression of IRS-1 and IRS- 2 decreased and the expression of PI3K and AMPK did not significantly differ between groups in the mice used in the experiment for the treatment of NAFLD. In addition, the expression levels of gluconeogenic genes, such as PEPCK and G6Pase were significantly different in the mice used in the experiment for the treatment of NAFLD. These results suggest that, whereas the early administration of teneligliptin may improve insulin resistance, the administration of the drug after the occurrence of a certain degree of steatosis does little to improve the insulin resistance. These results are suggested to be one of the factors contributing to the histological differences between the two groups.

Since the GLP-1 concentration and DPP-4 activity in the groups receiving teneligliptin were at similar levels, we hypothesized that pathways unlike GLP-1 and DPP-4 activity were responsible for the results in our experiment. An important difference in the two experimental groups was the existence of excess adiposity, including hepatic steatosis that was caused by 4 weeks of being fed a HCD. In addition to adipocytokine secreted from adipose tissue, our results suggested that the DPP-4 inhibitor aggravatd the expression of certain proinflamatory cytokines in the presence of hepatic steatosis. This result may be associated with the aggravation of insulin resistance in teneligliptin group 2. We will have to examine the mechanisms of the effect of the DPP-4 inhibitor apart from DPP-4 activity and GLP-1 in detail in the future.

On the whole, it was shown that the administration of the DPP-4 inhibitor, teneligliptin, from the initial stage of diabetes may not only suppress the expression of a number of proinflammatory cytokines in the liver, but can also inhibit the expression of lipid synthesis-related genes and, secondarily, inhibit the occurrence of steatosis and prevent the development of NAFLD by preventing the expression of pro-inflammatory cytokines, lipid synthesis-related genes and improving insulin resistance.

In conclusion, the results of the present study suggest that the DPP-4 inhibitor, teneligliptin, may prevent the development of NAFLD, which is a hepatic phenotype of metabolic syndrome, if the drug is administered from the initial stage of diabetes. Since DPP-4 inhibitors are recommended to be used in the treatment of early-stage type 2 diabetes (34); it is considered important to use teneligliptin as rescommended. Further experiments are warranted in order to determine whether similar effects can be obtained with other DPP-4 inhibitors.

\section{Acknowledgements}

The authors would like to thank Yukio Nakahira and Eiko Koubayashi, at the Osaka Medical College, for providing technical support.

\section{References}

1. Matsuzawa Y: The role of fat topology in the risk of disease. Int J Obes 32 (Suppl 7): S83-S92, 2008. 
2. Ludwig J, Viggiano TR, McGill DB and Oh BJ: Nonalcoholic steatohepatitis: Mayo Clinic experiences with a hitherto unnamed disease. Mayo Clin Proc 55: 434-438, 1980.

3. Powell EE, Cooksley WG, Hanson R, Searle J, Halliday JW and Powell LW: The natural history of nonalcoholic steatohepatitis: A follow-up study of forty-two patients for up to 21 years. Hepatology 11: 74-80, 1990.

4. Yoshiike $\mathrm{N}$ and Lwin $\mathrm{H}$ : Epidemiological aspects of obesity and NASH/NAFLD in Japan. Hepatol Res 33: 77-82, 2005.

5. Ahrén B: Gut peptides and type 2 diabetes mellitus treatment. Curr Diab Rep 3: 365-372, 2003.

6. Drucker DJ: Biological actions and therapeutic potential of the glucagon-like peptides. Gastroenterology 122: 531-544, 2002.

7. Mentlein R, Gallwitz B and Schmidt WE: Dipeptidyl-peptidase IV hydrolyses gastric inhibitory polypeptide, glucagon-like peptide-1(7-36)amide, peptide histidine methionine and is responsible for their degradation in human serum. Eur J Biochem 214: 829-835, 1993.

8. Deacon CF, Johnsen AH and Holst JJ: Degradation of glucagon-like peptide-1 by human plasma in vitro yields an N-terminally truncated peptide that is a major endogenous metabolite in vivo. $\mathrm{J}$ Clin Endocrinol Metab 80: 952-957, 1995.

9. Ahrén B, Landin-Olsson M, Jansson PA, Svensson M, Holmes D and Schweizer A: Inhibition of dipeptidyl peptidase-4 reduces glycemia, sustains insulin levels, and reduces glucagon levels in type 2 diabetes. J Clin Endocrinol Metab 89: 2078-2084, 2004.

10. Pratley RE and Salsali A: Inhibition of DPP-4: A new therapeutic approach for the treatment of type 2 diabetes. Curr Med Res Opin 23: 919-931, 2007.

11. Vella A, Bock G, Giesler PD, Burton DB, Serra DB, Saylan ML, Dunning BE, Foley JE, Rizza RA and Camilleri M: Effects of dipeptidyl peptidase-4 inhibition on gastrointestinal function, meal appearance, and glucose metabolism in type 2 diabetes. Diabetes 56: 1475-1480, 2007.

12. Maiztegui B, Borelli MI, Madrid VG, Del Zotto H, Raschia MA Francini F, Massa ML, Flores LE, Rebolledo OR and Gagliardino JJ: Sitagliptin prevents the development of metabolic and hormonal disturbances, increased $\beta$-cell apoptosis and liver steatosis induced by a fructose-rich diet in normal rats. Clin Sci (Lond) 120: 73-80, 2011.

13. Yoshida T, Akahoshi F, Sakashita H, Kitajima H, Nakamura M, Sonda S, Takeuchi M, Tanaka Y, Ueda N, Sekiguchi S, et al Discovery and preclinical profile of teneligliptin (3-[(2S,4S)-4-[4(3-methyl-1-phenyl-1H-pyrazol-5-yl)piperazin-1-yl]pyrrolidin-2ylcarbonyl]thiazolidine): A highly potent, selective, long-lasting and orally active dipeptidyl peptidase IV inhibitor for the treatment of type 2 diabetes. Bioorg Med Chem 20: 5705-5719, 2012.

14. Friedman JM, Leibel RL, Siegel DS, Walsh J and Bahary N: Molecular mapping of the mouse ob mutation. Genomics 11: 1054-1062, 1991 .

15. Brunt EM, Janney CG, Di Bisceglie AM, Neuschwander-Tetri BA and Bacon BR: Nonalcoholic steatohepatitis: A proposal for grading and staging the histological lesions. Am J Gastroenterol 94: 2467-2474, 1999.

16. Tomas E, Wood JA, Stanojevic V and Habener JF. Glucagon-like peptide-1 (9-36) amide metabolite inhibits weight gain and attenuates diabetes and hepatic steatosis in diet-induce obese

17. Gao B: Innate immunity and steatohepatitis: A critical role of another toll (TLR-9). Gastroenterology 139: 27-30, 2010.

18. Dentin R, Girard J and Postic C: Carbohydrate responsive element binding protein (ChREBP) and sterol regulatory element binding protein-1c (SREBP-1c): Two key regulators of glucose metabolism and lipid synthesis in liver. Biochimie 87: 81-86, 2005 .
19. Foretz M, Guichard C, Ferré P and Foufelle F: Sterol regulatory element binding protein-1c is a major mediator of insulin action on the hepatic expression of glucokinase and lipogenesis-related genes. Proc Natl Acad Sci USA 96: 12737-12742, 1999.

20. Foretz M, Pacot C, Dugail I, Lemarchand P, Guichard C Le Lièpvre X, Berthelier-Lubrano C, Spiegelman B, Kim JB, Ferré $\mathrm{P}$ and Foufelle F: ADD1/SREBP-1c is required in the activation of hepatic lipogenic gene expression by glucose. Mol Cell Biol 19: 3760-3768, 1999.

21. Cohen P and Friedman JM: Leptin and the control of metabolism: Role for stearoyl-CoA desaturase-1 (SCD-1). J Nutr 134: 2455S-2463S, 2004.

22. Gastaldelli A, Harrison S, Belfort-Aguiar R, Hardies J, Balas B, Schenker S and Cusi K: Pioglitazone in the treatment of NASH: The role of adiponectin. Aliment Pharmacol Ther 32: 769-775, 2010.

23. Kersten S, Desvergne B and Wahli W: Roles of PPARs in health and disease. Nature 405: 421-424, 2000.

24. Knopp RH: Drug treatment of lipid disorders. N Engl J Med 341: 498-511, 1999.

25. Postic $\mathrm{C}$ and Girard J: Contribution of de novo fatty acid synthesis to hepatic steatosis and insulin resistance: Lessons from genetically engineered mice. J Clin Invest 118: 829-838, 2008.

26. Srere PA: The citrate cleavage enzyme. I. Distribution and purification. J Biol Chem 234: 2544-2547, 1959.

27. Abu-Elheiga L, Jayakumar A, Baldini A, Chirala SS and Wakil SJ: Human acetyl-CoA carboxylase: Characterization, molecular cloning, and evidence for two isoforms. Proc Natl Acad Sci USA 92: 4011-4015, 1995.

28. van der Leij FR, Kram AM, Bartelds B, Roelofsen H, Smid GB, Takens J, Zammit VA and Kuipers JR: Cytological evidence that the C-terminus of carnitine palmitoyltransferase I is on the cytosolic face of the mitochondrial outer membrane. Biochem J 341: 777-784, 1999.

29. Park EA, Mynatt RL, Cook GA and Kashfi K: Insulin regulates enzyme activity, malonyl-CoA sensitivity and mRNA abundance of hepatic carnitine palmitoyltransferase-I. Biochem J 310: $853-858,1995$

30. Bartlett K and Eaton S: Mitochondrial beta-oxidation. Eur J Biochem 271: 462-469, 2004

31. Hegarty BD, Turner N, Cooney GJ and Kraegen EW: Insulin resistance and fuel homeostasis: The role of AMP-activated protein kinase. Acta Physiol (Oxf) 196: 129-145, 2009.

32. Saltiel AR and Kahn CR: Insulin signalling and the regulation of glucose and lipid metabolism. Nature 414: 799-806, 2001.

33. Kubota N, Kubota T, Itoh S, Kumagai H, Kozono H, Takamoto I, Mineyama T, Ogata H, Tokuyama K, Ohsugi M, et al: Dynamic functional relay between insulin receptor substrate 1 and 2 in hepatic insulin signaling during fasting and feeding. Cell Metab 8: 49-64, 2008 .

34. Guo S, Copps KD, Dong X, Park S, Cheng Z, Pocai A, Rossetti L, Sajan M, Farese RV and White MF: The Irs1 branch of the insulin signaling cascade plays a dominant role in hepatic nutrient homeostasis. Mol Cell Biol 29: 5070-5083, 2009.

35. Cernea $\mathrm{S}$ and Raz I: Therapy in the early stage: Incretins. Diabetes Care 34 (Suppl 2): S264-S271, 2011.

36. Valera A, Pujol A, Pelegrin M and Bosch F: Transgenic mice overexpressing phosphoenolpyruvate carboxykinase develop non-insulin-dependent diabetes mellitus. Proc Natl Acad Sci USA 91: 9151-9154, 1994 